\title{
Tracking along-arc sediment inputs to the Aleutian arc using
}

\section{thallium isotopes}

9 Sune G. Nielsen ${ }^{1,2^{*}}$, Gene Yogodzinski ${ }^{2}$, Julie Prytulak ${ }^{3}$, Terry Plank ${ }^{4}$, Suzanne M. Kay ${ }^{5}$, Robert

${ }^{1}$ NIRVANA laboratories, Woods Hole Oceanographic Institution, Woods Hole, MA, USA ${ }^{2}$ Dept. of Geology and Geophysics, Woods Hole Oceanographic Institution, Woods Hole, MA, USA

${ }^{3}$ Department of Earth and Ocean Sciences, University of South Carolina, Columbia, SC, USA ${ }^{4}$ Department of Earth Science and Engineering, Imperial College London, UK ${ }^{5}$ Lamont Doherty Earth Observatory, Columbia University, NY, USA ${ }^{6}$ Department of Earth and Atmospheric Sciences, Cornell University, Ithaca, NY, USA

* corresponding author: snielsen@whoi.edu 
Abstract - Sediment transport from the subducted slab to the mantle wedge is an important

26 process in understanding the chemical and physical conditions of arc magma generation. The

27 Aleutian arc offers an excellent opportunity to study sediment transport processes because the

28 subducted sediment flux varies systematically along strike (Kelemen et al., 2003) and many

29 lavas exhibit unambiguous signatures of sediment addition to the sub-arc mantle (Morris et al.,

30 1990). However, the exact sediment contribution to Aleutian lavas and how these sediments are

31 transported from the slab to the surface are still debated. Thallium (Tl) isotope ratios have great

32 potential to distinguish sediment fluxes in subduction zones because pelagic sediments and low-

33 temperature altered oceanic crust are highly enriched in $\mathrm{Tl}$ and display heavy and light $\mathrm{Tl}$ isotope

34 compositions, respectively, compared with the upper mantle and continental crust.

35 Here, we investigate the $\mathrm{Tl}$ isotope composition of lavas covering almost the entire Aleutian

36 arc a well as sediments outboard of both the eastern (DSDP Sites 178 and 183) and central (ODP

37 Hole 886C) portions of the arc. Sediment Tl isotope compositions change systematically from

38 lighter in the Eastern to heavier in the Central Aleutians reflecting a larger proportion of pelagic

39 sediments when distal from the North American continent. Lavas in the Eastern and Central

40 Aleutians mirror this systematic change to heavier $\mathrm{Tl}$ isotope compositions to the west, which

41 shows that the subducted sediment composition is directly translated to the arc east of Kanaga

42 Island. Moreover, quantitative mixing models of $\mathrm{Tl}$ and $\mathrm{Pb}, \mathrm{Sr}$ and $\mathrm{Nd}$ isotopes reveal that bulk

43 sediment transfer of $\sim 0.6-1.0 \%$ by weight in the Eastern Aleutians and $\sim 0.2-0.6 \%$ by weight in

44 the Central Aleutians can account for all four isotope systems. Bulk mixing models, however,

45 require that fractionation of trace element ratios like $\mathrm{Ce} / \mathrm{Pb}, \mathrm{Cs} / \mathrm{Tl}$, and $\mathrm{Sr} / \mathrm{Nd}$ in the Central and

46 Eastern Aleutians occurs after the sediment component was mixed with the mantle wedge.

47 Models of $\mathrm{Sr}$ and $\mathrm{Nd}$ isotopes that involve sediment melting require either high degrees of 
48 sediment melting $(>50 \%$ ), in which case trace element ratios like $\mathrm{Ce} / \mathrm{Pb}, \mathrm{Cs} / \mathrm{Tl}$, and $\mathrm{Sr} / \mathrm{Nd}$ of

49 Aleutian lavas need to be produced after mixing with the mantle, or significant fluid additions

50 from the underlying oceanic crust with $\mathrm{Sr}$ and $\mathrm{Nd}$ isotope compositions indistinguishable from

51 the mantle wedge as well as high $\mathrm{Sr} / \mathrm{Nd}$ ratios similar to that of low $(<20 \%)$ degree sediment

52 melts.

53 Thallium isotope data from Western Aleutian lavas exhibit compositions slightly lighter than

54 the upper mantle, which implies a negligible sediment flux at this location and probably

55 involvement of low-temperature altered oceanic crust in the generation of these lavas. In general,

56 the lightest $\mathrm{Tl}$ isotope compositions are observed for the highest $\mathrm{Sr} / \mathrm{Y}$ ratios and most

57 unradiogenic $\mathrm{Sr}$ and $\mathrm{Pb}$ isotope compositions, which is broadly consistent with derivation of

58 these lavas via melting of eclogitized altered oceanic crust. 


\section{Introduction}

60 Volcanic arcs are the surface expression of plate subduction, which controls the transfer of

61 volatiles and other chemical heterogeneities into Earth's mantle. Subduction zones are also the

62 centers of the most pronounced natural hazards on Earth due to their frequent volcanic eruptions

63 as well as great earthquakes. It is therefore important to understand the physical and chemical

64 mechanisms that are responsible for generating volcanic arcs.

65 Material erupted from arc volcanoes are derived from two principal sources: The subducting

66 slab and the mantle wedge located between the slab and arc crust. While the mantle wedge often

67 is considered to consist of relatively homogenous depleted peridotite, the subducting slab is

68 highly heterogeneous, and it is uncertain which portions of it are released into the volcanic arc

69 and which portions are ultimately subducted into the deep mantle (Ryan and Chauvel, 2014). The

70 subducting slab contains sediments, variably altered oceanic crust (AOC), ultramafic cumulates

71 and mantle rocks, some of which may be substantially hydrated. Uncertainties associated with

72 determining mass fluxes from the slab make it difficult to construct models of the distribution

73 and origin of chemical and physical heterogeneities in the deep Earth and thereby understanding

74 mantle geodynamics and terrestrial volatile budgets.

75 Sediments are known to contribute to many arc lavas (Carpentier et al., 2008; Morris et al.,

76 1990; Plank, 2005; Tera et al., 1986), but their exact fluxes from the slab are particularly difficult

77 to quantify, in part because they likely represent a very small fraction of the material contained

78 in arc lavas (Ben Othmann et al., 1989; Kay, 1980; Thirlwall et al., 1996; White and Dupré,

79 1986). Sediments may also be scraped off the slab into forearc accretionary complexes along

80 some margins (Von Huene and Scholl, 1991). At the same time, sediments often contain very

81 high concentrations of many trace elements compared with the mantle wedge (Ben Othmann et 
82 al., 1989; Plank and Langmuir, 1998), which could enable detection of even minor sediment

83 additions to arc lavas. However, many of these trace elements may be strongly affected by

84 retention in accessory mineral phases that likely exist in the slab (Hermann and Rubatto, 2009;

85 Johnson and Plank, 1999; Skora and Blundy, 2010), which further complicates the assessment of

86 sediment contributions to volcanic arcs.

87 The Aleutian arc provides an excellent opportunity to study geochemical fluxes from slab to 88 surface because previous studies have shown that subducted marine sediments unambiguously 89 contribute to most Aleutian lavas (Kay and Kay, 1994; Morris et al., 1990; Plank, 2005; Sun,

90 1980; Tera et al., 1986). In addition, there is a systematic decrease in subduction rate from east to

91 west while only relatively minor variations occur in the overall sediment thickness subducted

92 along the main arc (e.g. Kelemen et al., 2003). Thus, the sediment subduction flux is thought to

93 be highest in the east and almost absent in the westernmost portions of the arc (Kay and Kay,

94 1994). The question, however, is whether the sedimentary flux beneath the arc is also reflected in

95 the magnitude of the sediment component in the arc volcanic rocks and, hence, if the fraction of

96 sediment removed from the slab to the arc is independent of total sediment subduction flux.

97 Several studies have also suggested that the chemical characteristics of the subducted sediment

98 are likely to change along the arc from thick continental detrital in the east (turbidites of the

99 Zodiac and Surveyor fans) to abyssal pelagic clays in the central Aleutians (Kay and Kay, 1988;

100 Kay and Kay, 1994; Sun, 1980; Yogodzinski et al., 2011), which should be manifested in the

101 isotopic characteristics of Aleutian lavas. However, this trait has yet to be confirmed, partially

102 because no direct measurements of pelagic sediments outboard of the Central Aleutians have 103 been conducted to date. 
An additional interesting feature of the Aleutian arc is the presence of lavas that may reflect

105 melting of eclogitized subducted oceanic crust due to their high silica, high $\mathrm{Sr} / \mathrm{Y}$, and

106 unradiogenic $\mathrm{Pb}$ and $\mathrm{Sr}$ isotope compositions (Kay, 1978; Yogodzinski et al., 2015; Yogodzinski

107 et al., 1995; Yogodzinski et al., 2001). These lavas are predominant in the Western part of the arc

108 with Miocene-age examples from Adak Island (Kay, 1978) giving rise to the name of the rock

109 type adakites (Defant and Drummond, 1990).

110 Here we use thallium (Tl) isotope ratios to assess sediment fluxes to the Aleutian arc.

111 Thallium isotopes have great potential to quantify fluxes from the slab because modern pelagic

112 sediments are highly enriched in $\mathrm{Tl}$ and display isotopic compositions that are heavier than the

113 isotopically homogeneous upper mantle (Nielsen and Rehkämper, 2011; Prytulak et al., 2013;

114 Rehkämper et al., 2004). Oceanic crust altered by hydrothermal fluids at low temperatures

$115\left(<100^{\circ} \mathrm{C}\right)$, on the other hand, display light $\mathrm{Tl}$ isotope compositions coupled with high $\mathrm{Tl}$

116 concentrations (Coggon et al., 2014; Nielsen et al., 2006c). Therefore, the diversity of previously

117 inferred source regions of the Aleutian arc provides an ideal setting to employ $\mathrm{Tl}$ isotopes as a 118 slab component tracer.

\section{2. Thallium isotope background}

121 Thallium is a trace metal that displays both lithophile and chalcophile behaviors. In 122 geochemical studies, it is often grouped with the alkali elements $\mathrm{K}, \mathrm{Rb}$, and Cs due to their 123 similar ionic radii and charge (Heinrichs et al., 1980; Shannon, 1976; Shaw, 1952). However, a 124 recent study found that $\mathrm{Tl}$ is compatible in mantle sulfides and therefore has a higher bulk 125 partition coefficient during mantle melting than do the alkali metals (Nielsen et al., 2014). 126 Nonetheless, $\mathrm{Tl}$ is incompatible during mantle melting and is enriched in the continental crust 
$127(\sim 300-500 \mathrm{ng} / \mathrm{g})$ relative to the mantle $(\sim 0.5-2 \mathrm{ng} / \mathrm{g})$ and mid ocean ridge basalts $(\sim 2-20 \mathrm{ng} / \mathrm{g})$

128 (Nielsen et al., 2005; Nielsen et al., 2014; Wedepohl, 1995).

129 Thallium has two stable isotopes with masses 203 and 205. Thallium isotope compositions

130 are reported relative to the NIST SRM $997 \mathrm{Tl}$ standard in parts per 10,000 such that

$$
\varepsilon^{205} \mathrm{Tl}=10,000 \times\left({ }^{205} \mathrm{Tl}^{203} \mathrm{Tl}_{\text {sample }}{ }^{205} \mathrm{Tl}{ }^{203} \mathrm{Tl} \text { SRM } 997\right) /\left({ }^{205} \mathrm{Tl} /{ }^{203} \mathrm{Tl} \text { SRM 997 }\right)
$$

It is thought that the small relative mass difference between the two isotopes prevents 133 extensive isotopic fractionation in all but a select few environments, which may be linked to 134 nuclear volume isotope fractionation that occurs in chemical reactions primarily involving both 135 oxidation states of $\mathrm{Tl},+1$ and +3 (Nielsen and Rehkämper, 2011; Schauble, 2007). Trivalent Tl, 136 however, is not likely to be thermodynamically stable in the igneous environments including the 137 mantle given that $\mathrm{Tl}$ dissolved in oxic seawater is exclusively univalent (Byrne, 2002; Nielsen et 138 al., 2009). The univalent $\mathrm{Tl}$ redox state of the mantle renders the average upper mantle 139 homogenous with respect to $\mathrm{Tl}$ isotopes $\left(\varepsilon^{205} \mathrm{Tl}_{\mathrm{MORB}}=-2 \pm 0.5\right.$; (Nielsen et al., 2006b)) because 140 no significant isotope fractionation is expected during melting or fractional crystallization 141 (Schauble, 2007). In contrast, hydrothermally altered oceanic crust and metalliferous marine 142 sediments are highly variable with respect to $\mathrm{Tl}$ isotope ratios and concentrations.

143 Enrichment of $\mathrm{Tl}$ in marine sediments is primarily due to adsorption onto authigenic 144 manganese (Mn) oxides (Hein et al., 2000; Nielsen et al., 2013; Rehkämper et al., 2004; 145 Rehkämper et al., 2002) that precipitate ubiquitously from oxic seawater onto sedimentary 146 particles. This adsorption process is responsible for heavy $\mathrm{Tl}$ isotope compositions detected in 147 pelagic clays of $\varepsilon^{205} \mathrm{Tl}>2$ (Rehkämper et al., 2004) and is probably linked to surface oxidation 148 of Tl during adsorption to Mn oxides (Nielsen et al., 2013; Peacock and Moon, 2012). Rates of 149 Mn oxide precipitation are very slow, thus the abundance of Mn oxides in sediments generally 
150 inversely correlates with sediment depositional rates. This process renders sediments deposited 151 close to continents or underneath highly productive water masses depleted in $\mathrm{Tl}$ associated with

152 Mn oxides and consequently such sediments are characterized by $\varepsilon^{205} \mathrm{Tl} \sim-2$, akin to the 153 continental crust and the upper mantle (Nielsen et al., 2006b; Nielsen et al., 2005; Nielsen et al., 154 2006c).

155 In the basaltic oceanic crust, $\mathrm{Tl}$ enrichment occurs within the upper few hundred meters of 156 the oceanic crust during the circulation of seawater at low temperatures $\left(<100^{\circ} \mathrm{C}\right)$. Thallium 157 enrichment may be related to biologically mediated pyrite precipitation (Coggon et al., 2014) or 158 alternatively to $\mathrm{Tl}$ partitioning into alkali-rich clay minerals that also form during low 159 temperature alteration (Nielsen et al., 2006c). Analysis of $\mathrm{Tl}$ concentrations and isotope 160 compositions in low-T altered crust from IODP Hole U1301B, Deep Sea Drilling Project 161 (DSDP) Hole 417D and DSDP/Ocean Drilling Project (ODP) Hole 504B showed high Tl 162 concentrations (30-1000 ng/g) and light $\mathrm{Tl}$ isotope ratios (down to $\varepsilon^{205} \mathrm{Tl} \sim-15$; (Coggon et al., 163 2014; Nielsen et al., 2006c)). Conversely, the sheeted dike portion of the oceanic crust is 164 depleted in $\mathrm{Tl}(<1 \mathrm{ng} / \mathrm{g}$; (Nielsen et al., 2006c)), which is the result of hydrothermal fluid 165 circulation at high temperature $\left(300-400^{\circ} \mathrm{C}\right)$ near the ridge axis that drives extraction rather than 166 deposition of $\mathrm{Tl}$. This process does not appear to cause isotope fractionation, however, as sheeted 167 dikes have $\varepsilon^{205} \mathrm{Tl}$ similar to MORB glass $\left(\varepsilon^{205} \mathrm{Tl} \sim-2 \pm 0.5\right.$; (Nielsen et al., 2006b; Nielsen et al., 168 2006c)).

169 The Tl isotope systematics of marine sediments and oceanic crust combined with previous 170 studies of the Aleutian arc allow some general predictions to be made about what $\mathrm{Tl}$ isotope 171 compositions to expect in different portions of the Aleutian arc. Sediment fluxes from the slab 172 have been inferred to account for the majority of the observed trace element and isotopic 
173 enrichments in the eastern and central portions of the arc (Kay et al., 1978; Kelemen et al., 2003;

174 Yogodzinski et al., 2011). The turbidites of the Surveyor and Zodiac fans (Fig, 1) supply

175 primarily detrital sediments to the eastern portion of the arc, while the Central Aleutians are

176 sufficiently distal to any continent that slowly accumulating pelagic clays become the dominant

177 sediment type in that region. Given that $\mathrm{Tl}$ isotope compositions of detrital sediments $\left(\varepsilon^{205} \mathrm{Tl} \sim\right.$ -

178 2) and pelagic clays $\left(\varepsilon^{205} \mathrm{Tl}>0\right)$ are distinct, we might expect the Central Aleutians to display

179 somewhat heavier $\mathrm{Tl}$ isotope compositions than do the Eastern Aleutians. The Western

180 Aleutians, on the other hand, are often inferred to have almost negligible sediment input. Instead,

181 adakitic lavas that may be derived from melting of the down-going oceanic crust are common

182 (Yogodzinski et al., 2015; Yogodzinski et al., 2001). If the upper volcanic portion of the oceanic

183 crust that has previously been hydrothermally altered at low temperatures takes part in these

184 melting processes, then $\mathrm{Tl}$ isotope compositions of $\varepsilon^{205} \mathrm{Tl}<-2$ are expected.

185

186 3. Samples

187 3.1. Aleutian lavas

188 Lava samples from the east and central Aleutians (from Okmok, Westdahl, Moffett and

189 Kanaga volcanoes) were originally chosen to explore Th-Nb-REE variations with high quality

190 ICP-MS analyses, and are the same as those published and discussed in Plank (2005) and Kay

191 and Kay (1994). This subset of Aleutian volcanic rocks form a tight linear trend in Th/La-Sm/La

192 that were interpreted to derive from simple binary mixing between mantle and a sedimentary

193 component that is nearly identical to the DSDP 183 sediment average. These samples thus show

194 clear evidence for subducting sediment in their source, largely of continental detrital (high

$195 \mathrm{Th} / \mathrm{La})$ origin. 
197 westernmost emergent volcano in the Aleutian arc (Fig. 1). The samples are from volcanic cones

198 of the Ingenstrem Depression, a rectangular-shaped structural depression immediately west of

199 Buldir, and from the Western Cones area, which is located 200-300 km further west. Ages of the

200 samples are uncertain, but all were dredged from constructional volcanic edifices which, based

201 on available dating, appear to be no more than 500-600 ka years old (Yogodzinski et al., 2015).

202 Petrographic observations indicate that the samples are fresh and apparently unaffected by

203 weathering or other alteration processes. Additional details, including geochemical methods,

204 complete whole-rock compositions, petrographic descriptions and photomicrographs are 205 provided in Yogodzinski et al. (2015).

\subsection{Sediment samples}

208 Thallium isotope compositions and concentrations were determined for discrete sediment 209 samples from Deep Sea Drilling Program (DSDP) Sites 178 and 183 and Ocean Drilling 210 Program (ODP) Hole 886C (Fig. 1).

211 Sites 178 and 183 are both located outboard of the eastern portion of the Aleutian arc with 212 DSDP Site 178 located in the Gulf of Alaska and therefore slightly to the east of the Aleutian 213 islands, but representative of sediments of the Surveyor Fan. The samples analyzed here from 214 DSDP 178 have previously been investigated for both trace elements and some radiogenic 215 isotope ratios (Plank and Langmuir, 1998; Vervoort et al., 2011). Samples from DSDP 183 are 216 new samples that were obtained from core depths adjacent $(2 \mathrm{~cm})$ to the samples that had 217 previously been used to assess the composition of subducted sediment in the Aleutians (Kay and 218 Kay, 1988; Plank and Langmuir, 1998; Vervoort et al., 2011; Von Drach et al., 1986). 
Sediment samples from ODP Hole 886C were also obtained, which is located outboard of

220 the Central Aleutians on the abyssal plain at $44^{\circ} 41.384^{\prime} \mathrm{N}, 168^{\circ} 14.416^{\prime} \mathrm{W}$. The sediment

221 thickness in this location is $\sim 70 \mathrm{~m}$ with an estimated maximum age of $\sim 80 \mathrm{Ma}$ (Snoeckx et al.,

222 1995). However, the upper $\sim 50 \mathrm{~m}$ were deposited in the last 10 million years while the bottom

$223 \sim 20 \mathrm{~m}$ are characterized by several hiatuses and very slow deposition rates (Snoeckx et al., 1995).

224 We selected 15 samples at approximately evenly distributed intervals (Table 1). Each sample

225 was selected by visual inspection of core barrels in order to obtain the most representative

226 samples from each section. The types of sediment analyzed range from diatom ooze to dark

227 brown pelagic clay. Several ferromanganese (Fe-Mn) nodules are also found in Hole 886C and

228 because such nodules often contain large enrichments of many trace metals we also selected one

229 of these here $(886 \mathrm{C} 6 \mathrm{H}-3120-122 \mathrm{~cm})$ to assess the effect on the trace element budget in the

230 average subducted sediment composition. A single sample from the uppermost altered basaltic

231 basement at Site 886B (Table 1) was also obtained in order to potentially assess the composition

232 of the hydrothermally altered basaltic crust in the Central Aleutians.

\section{4. Methods}

\section{4.1. Sample preparation and chemical separation of $\mathrm{Tl}, \mathrm{Sr}, \mathrm{Nd}$ and $\mathrm{Pb}$}

236 The eastern and central Aleutian lavas were powdered as part of the study in Kay and Kay 237 (1994) and Plank (2005) in an alumina ball mill to eliminate $\mathrm{Nb}-\mathrm{Ta}$ contamination in samples

238 previously powdered in tungsten carbide. Sediment samples from ODP Hole 886C were dried in 239 an oven at $80^{\circ} \mathrm{C}$ overnight before powdering in an agate swing mill. The swing mill was cleaned 240 with high purity quartz before and after each run, triple rinsed with deionized water and air dried 241 to avoid cross-contamination. Lavas from the Western Aleutians consist of submarine dredges 
242 primarily from the Ingenstrom depression $\left(\sim 52^{\circ} 30^{\prime} \mathrm{N}, 175^{\circ} \mathrm{W}\right)$ were obtained as rock fragments

243 of $\sim 50 \mathrm{~g}$. Due to potential alteration by interaction with seawater and possible contamination with

244 Fe-Mn minerals precipitated from seawater, we did not powder these samples. Instead each

245 sample was fractured into mm-sized chips. These were handpicked under a binocular microscope

246 to select pieces devoid of alteration and Fe-Mn minerals. The rock chips were then ultrasonicated

247 in MQ water to remove any dust or superficial contaminants. Additional tests were also

248 performed on a subset of the Western Aleutian lavas in order to investigate if alteration or Fe-Mn

249 minerals were present in the otherwise visually pure rock chips. These tests involved separating

250 three additional aliquots of rock chips. These three splits were 1) dissolved without further

251 preparation, 2) ultrasonicated for 1 hour in $1 \mathrm{M}$ distilled $\mathrm{HCl}$ prior to dissolution and 3)

252 ultrasonicated for one hour in $6 \mathrm{M}$ distilled $\mathrm{HCl}$ prior to dissolution. For two of the $1 \mathrm{M} \mathrm{HCl}$

253 leachates sufficient $\mathrm{Tl}$ was present for $\mathrm{Tl}$ isotope analysis.

254 Chips as well as powdered samples (0.1-0.3g) were dissolved in a 1:1 mixture of 255 concentrated distilled $\mathrm{HF}$ and $\mathrm{HNO}_{3}$ on a hotplate overnight. Following this, they were dried and

256 fluxed several times with concentrated distilled nitric acid and hydrochloric acid until the

257 fluorides that formed during the first step could no longer be seen. Separate powder splits of the

258 Central Aleutian lavas were dissolved for $\mathrm{Tl}, \mathrm{Sr}, \mathrm{Nd}$ and $\mathrm{Pb}$ isotopes. Following complete

259 dissolution of fluorides, samples were dried on a hotplate and taken up in appropriate acid

260 matrices for separation of $\mathrm{Tl}, \mathrm{Sr}, \mathrm{Nd}$ and $\mathrm{Pb}$, respectively. Isolation of $\mathrm{Tl}, \mathrm{Sr}, \mathrm{Nd}$ and $\mathrm{Pb}$ from

261 sample matrix followed previously published ion exchange chromatographic methods (Baker et

262 al., 2009; Jackson and Hart, 2006; Lugmair and Galer, 1992; Nielsen et al., 2004; Rehkämper

263 and Halliday, 1999; Scher and Delaney, 2010). Strontium was separated and purified from

264 samples using Sr-Spec (Eichrom ${ }^{\circledR}$ Technologies, Inc.) resin. Neodymium chemistry was done 
265 with LN resin (Eichrom ${ }^{\circledR}$ Technologies, Inc.) following methods described in Scher and Delaney

266 (2010). Lead chemistry utilized the $\mathrm{HBr}-\mathrm{HNO}_{3}$ procedure of Lugmair and Galer (1992) and

267 Abuchami et al. (1999). The Tl separation procedure has been shown to produce quantitative

268 yields (Nielsen et al., 2004; Nielsen et al., 2006a; Rehkämper et al., 2004) and these can

269 therefore be converted to $\mathrm{Tl}$ concentrations. Total procedural $\mathrm{Tl}$ blanks during this study were

$270<3 p g$, which is insignificant compared to the indigenous Tl processed for the samples of $>3 \mathrm{ng}$.

271 Total chemistry blanks for $\mathrm{Sr}, \mathrm{Nd}$ and $\mathrm{Pb}$ were 60pg, 5pg and 50pg, respectively, which is

272 significantly less than the minimum amounts processed of $15 \mu \mathrm{g}, 1 \mu \mathrm{g}$, and 200ng, respectively.

273

274 4.2. Determination of $T l$ isotope compositions and concentrations

275 The $\mathrm{Tl}$ isotope compositions were determined at the WHOI Plasma Mass Spectrometry 276 Facility using a Thermo Finnigan Neptune multiple collector inductively coupled plasma-mass 277 spectrometer (MC-ICPMS). Previously described techniques that utilize both external 278 normalization to NIST SRM $981 \mathrm{~Pb}$ and standard-sample bracketing were applied for mass bias 279 correction (Nielsen et al., 2004; Rehkämper and Halliday, 1999). Due to the quantitative yields 280 of $\mathrm{Tl}$ from the column chemistry procedure, $\mathrm{Tl}$ concentrations were determined by monitoring 281 the ${ }^{205} \mathrm{Tl}$ signal intensities of the samples during the isotopic measurements. A known quantity of 282 NIST SRM $981 \mathrm{~Pb}$ was added to the sample $\mathrm{Tl}$ and the measured ${ }^{205} \mathrm{Tl} /{ }^{208} \mathrm{~Pb}$ ratios were then 283 converted directly into Tl abundances. Previous studies (Nielsen et al., 2007; Nielsen et al., 284 2006b; Nielsen et al., 2006c) that utilized the Nu Plasma MC-ICPMS applied a 5\% correction 285 that assumed $\mathrm{Tl}$ ionises 5\% more efficiently than $\mathrm{Pb}$. However, we have not been able to verify 286 this behavior for the Neptune and thus do not apply this correction here. The uncertainty on the $287 \mathrm{Tl}$ concentration measurements is likely on the order of $\pm 10 \%$ (2sd) (Prytulak et al., 2013). 
During the course of this study we evaluated the external $\mathrm{Tl}$ isotope reproducibility with repeat

289 analyses of USGS reference basalt powder BHVO-1, which was found to have an isotope 290 composition of $\varepsilon^{205} \mathrm{Tl}=-3.5 \pm 0.5$ (2sd) (Nielsen et al., 2015). Although individual $\mathrm{Tl}$ isotope 291 analyses have internal counting statistical uncertainties of about $0.07-0.15 \varepsilon^{205}$ Tl-units (1se), we

292 apply the external 2 sd reproducibility of $0.5 \varepsilon^{205} \mathrm{Tl}$-units to all unknowns because this uncertainty 293 accounts for all possible sources of error including sample dissolution, ion exchange 294 chromatography and mass spectrometric procedures (Nielsen et al., 2004).

\subsection{Determination of $\mathrm{Sr}, \mathrm{Nd}$ and $\mathrm{Pb}$ isotope compositions}

Strontium, $\mathrm{Nd}$ and $\mathrm{Pb}$ isotopic measurements were performed on a Thermo Finnigan 298 Neptune MC-ICPMS at the WHOI Plasma Mass Spectrometry Facility. For Sr isotope 299 measurements, isobaric interferences of ${ }^{87} \mathrm{Rb}$ on ${ }^{87} \mathrm{Sr}$ and ${ }^{86} \mathrm{Kr}$ on ${ }^{86} \mathrm{Sr}$ were corrected for by 300 monitoring ${ }^{82} \mathrm{Kr},{ }^{83} \mathrm{Kr}$ and ${ }^{85} \mathrm{Rb}$. Mass bias was corrected for with the exponential mass 301 fractionation law assuming ${ }^{86} \mathrm{Sr} /{ }^{88} \mathrm{Sr}=0.1194$, with a secondary correction to the $\mathrm{Sr}$ standard 302 NIST SRM $987\left({ }^{87} \mathrm{Sr} /{ }^{86} \mathrm{Sr}=0.710214\right)$ (Jackson and Hart, 2006). These secondary corrections 303 were always smaller than $40 \mathrm{ppm}$. The internal precision for $\mathrm{Sr}$ isotopic measurements was 8-14 304 ppm (2se), while repeat measurements of the NIST SRM 987 standard yielded external precision 305 of $\sim 25 \mathrm{ppm}(2 \mathrm{se})$.

306 For Nd isotope measurements, ${ }^{147} \mathrm{Sm}$ and ${ }^{149} \mathrm{Sm}$ were monitored to correct for the ${ }^{144} \mathrm{Sm}$ 307 interference on ${ }^{144} \mathrm{Nd}$. The interference corrected $\mathrm{Nd}$ isotope data were internally corrected for 308 mass bias using the exponential mass bias law, assuming ${ }^{146} \mathrm{Nd} /{ }^{144} \mathrm{Nd}=0.7219$, with a secondary 309 correction to JNdi-1 $\left({ }^{143} \mathrm{Nd} /{ }^{144} \mathrm{Nd}=0.512104\right.$, (Tanaka et al., 2000)). These secondary corrections 
310 were always smaller than $20 \mathrm{ppm}$. The internal precision of individual analyses was $8-12 \mathrm{ppm}$

311 (2se) and the external precision, assessed through repeat analyses of JNdi-1, was $\sim 15$ ppm (2se).

312 Lead isotope compositions were externally normalized for instrumental mass bias relative to

$313{ }^{205} \mathrm{Tl} /{ }^{203} \mathrm{Tl}=2.3871$ for the NIST SRM $997 \mathrm{Tl}$ standard and were also corrected using

314 measurements of NIST SRM 981 using values from Todt et al. (1996). The Pb isotopic ratios

315 have internal precision of $15-60 \mathrm{ppm}$ for ${ }^{206} \mathrm{~Pb} /{ }^{204} \mathrm{~Pb},{ }^{207} \mathrm{~Pb} /{ }^{204} \mathrm{~Pb}$, and ${ }^{208} \mathrm{~Pb} /{ }^{204} \mathrm{~Pb}$. External

316 reproducibility was assessed through repeat measurements of NIST SRM 981 and range from 17

$317 \mathrm{ppm}(2 \mathrm{se})$ for ${ }^{207} \mathrm{~Pb} /{ }^{206} \mathrm{~Pb}$ to $120 \mathrm{ppm}(2 \mathrm{se})$ for ${ }^{208} \mathrm{~Pb} /{ }^{204} \mathrm{~Pb}$.

318 The well-characterized USGS rock standard BHVO-1 was dissolved, processed, and 319 analyzed along with unknowns. Results for $\mathrm{Pb}, \mathrm{Sr}$ and $\mathrm{Nd}$ isotopic measurements of the BHVO-1 320 rock standard (Table S1) are within error of those reported in Weis et al. (Weis et al., 2006; $3212005)$.

\subsection{Trace element concentration analyses}

324 The Eastern and Central Aleutian lavas were digested and analyzed by ICP-MS, as 325 described and given in Plank (2005). DSDP 183 and 178 sediments were analyzed by INAA, 326 DCP and ICP-MS sediments as described and presented in Kay and Kay (1988), Plank and 327 Langmuir (1998) and Vervoort et al (2011), respectively. The ODP 886C sediments were 328 analyzed by ICP-MS and ICP-ES at Lamont-Doherty Earth Observatory as part of this study, 329 following procedures described in Rabinowitz et al (2015). Calibration standards and data 330 quality are as reported in Rabinowitz et al. (2015). Notably, thallium concentrations were 331 determined to within $3 \%$ relative standard deviation based on three separate digestions of the 332 Indian Ocean Radiolarian Clay $(407 \pm 11 \mathrm{ng} / \mathrm{g})$. 


\section{5. Results}

Thallium isotopic variation in the Eastern and Central Aleutian Islands (Unimak to Kanaga,

336 Fig. 1) ranges from $\varepsilon^{205} \mathrm{Tl}=-3.8$ to +2.6 (Table 2). The vast majority of samples, however, have

337 values that are within error of or heavier than the average upper mantle and continental crust

$338\left(\varepsilon^{205} \mathrm{Tl}=-2\right)$. The largest spread in $\mathrm{Tl}$ isotope compositions are found in samples from Adak and

339 Kanaga islands whereas samples in the eastern Aleutians tend to cluster around the value for

340 average upper mantle and continental crust $\left(\varepsilon^{205} \mathrm{Tl}=-2\right)$. Samples in this study from Adak and

341 Kanaga islands also cover the largest range in age (Kay and Kay, 1994), which may partially

342 account for the larger $\mathrm{Tl}$ isotope diversity. For the most mafic lavas $\left(\mathrm{SiO}_{2}<54 \%\right), \mathrm{Tl}$

343 concentrations range between 25 and $97 \mathrm{ng} / \mathrm{g}$, which is significantly enriched compared to 2-20

$344 \mathrm{ng} / \mathrm{g}$ observed for most MORB (Jenner and O'Neill, 2012; Nielsen et al., 2014).

345 Lavas from the Western Aleutians are characterized by lighter $\mathrm{Tl}$ isotope compositions than

346 the Central and Eastern Aleutians with most samples exhibiting $\varepsilon^{205} \mathrm{Tl}=-3.4$ to -1.5 . Two

347 samples have somewhat heavier $\mathrm{Tl}$ isotope compositions close to $\varepsilon^{205} \mathrm{Tl}=0$ while one sample is

348 very light at $\varepsilon^{205} \mathrm{Tl}=-9.3$ (Table 3 ). Thallium concentrations in the Western Aleutian lavas

349 overlap with those recorded for basaltic samples from the Eastern and Central Aleutians, but also

350 extends up to $470 \mathrm{ng} / \mathrm{g}$ for the very light sample. It is important to note that repeat analyses of

351 Western Aleutian lavas often showed a range of concentrations (Table 3). Some of this variation

352 can possibly be ascribed to the presence of contamination from Fe-Mn minerals or alteration via

353 interaction with seawater. However, a large fraction of this variation is clearly unrelated to these

354 secondary processes as the four different analyses of sample TN182_07_002 varies by more than

355 a factor of five (Table 3). The most likely explanation for the large concentration differences is 
that the Western Aleutian rocks are crystalline with a mixture of mineral grains up to several $\mathrm{mm}$

357 in diameter and groundmass (Yogodzinski et al., 2015). Each Tl isotope analysis was performed

358 on separately handpicked rock chips, not from a homogenized rock powder. Most igneous

359 minerals (olivine, pyroxene, plagioclase, amphibole) likely contain very low $\mathrm{Tl}$ concentrations

360 (Adam and Green, 2006) and, hence, it is expected that samples are heterogeneous on the mm-

361 scale with respect to $\mathrm{Tl}$ concentrations. With this caveat in mind, we emphasize that element

362 ratios involving $\mathrm{Tl}$ for Western Aleutian samples likely have uncertainties that approach a factor

363 of two. All other $\mathrm{Tl}$ isotope analyses were performed on homogenous rock powders and are

364 therefore not prone to effects of heterogeneity.

365 Sediments outboard of the Aleutian arc display $\mathrm{Tl}$ isotope compositions from $\varepsilon^{205} \mathrm{Tl}=-3.1$ to

$366+10.9$ (Table 4), while $\mathrm{Tl}$ concentrations also vary strongly between 55 to $20000 \mathrm{ng} / \mathrm{g}$.

367 Although most samples fall in the range from $\varepsilon^{205} \mathrm{Tl}=-3$ to -1 , there is a clear tendency for the

368 most $\mathrm{Tl}$-rich samples to display the heaviest $\mathrm{Tl}$ isotope compositions (Fig. 2). In addition, it is

369 evident that samples from ODP Site 886C exhibit, on average, heavier $\mathrm{Tl}$ isotope compositions

370 and higher $\mathrm{Tl}$ concentrations than do the sediments from DSDP 178 and 183 (Fig. 2), which is

371 clearly related to the high abundance of Fe-Mn minerals in certain sections of ODP Site 886C

372 sediments. Another striking feature of the pelagic sediments from ODP Site 886C outboard of

373 the Central Aleutians is that ${ }^{206} \mathrm{~Pb} /{ }^{204} \mathrm{~Pb}$ and ${ }^{208} \mathrm{~Pb} /{ }^{204} \mathrm{~Pb}$ isotope compositions of many samples

374 are significantly less radiogenic than those found in DSDP Holes 178 and 183 that are further to

375 the east (Table 4). This effect is likely due to the presence of Pb-rich Fe-Mn minerals that

376 precipitate directly from North Pacific seawater, which is thought to have been unradiogenic

377 throughout the Cenozoic (Ling et al., 1997; Ling et al., 2005). In addition, the oldest and most

$378 \mathrm{~Pb}$-enriched pelagic sediments in Hole $886 \mathrm{C}$ also display very unradiogenic ${ }^{207} \mathrm{~Pb} /{ }^{204} \mathrm{~Pb}$, which 
379 could indicate $\mathrm{Pb}$ inputs to seawater from MORB hydrothermal sources at this location.

380 However, due to the large uncertainties on the sediment ages in the lower portion of ODP Hole

381 886C (Snoeckx et al., 1995) it is difficult to assess to what extent these sediments contain

382 sufficient $\mathrm{Pb}$ to significantly affect the bulk subducted sediment ${ }^{207} \mathrm{~Pb} /{ }^{204} \mathrm{~Pb}$ isotope composition.

383 Here we use the trace element concentrations and isotope compositions determined for

384 sediments outboard of the Aleutian Islands to construct weighted average subducted sediment

385 compositions for the eastern and central Aleutians (Table 5). The averages were also weighted

386 by lithological abundance and density (Table 1), which was determined based on sediment

387 descriptions and core barrel photographs (Rea et al., 1993). It is assumed that the sediment pile

388 found at ODP Hole $886 \mathrm{C}$ is similar to what has been subducted in the Central Aleutians for the

389 past at least 10 Ma. This assumption is reasonable because the sediment depositional

390 environments as a function of distance from the Aleutian arc in the direction of the plate motion

391 have likely remained relatively constant over this time period. That is, the North Pacific is

392 characterized by relatively high productivity resulting in diatom rich sediments whereas the

393 Central Pacific gyres display low productivity and, therefore, are dominated by abyssal red clays.

394 Below we use the average subducted sediment components to investigate how changing 395 sediment composition along the Aleutian arc affects the composition of erupted lavas.

\section{6. Discussion}

398 6.1. Thallium isotopic variation induced by secondary processes

399 The $\mathrm{Tl}$ isotope compositions and concentrations recorded in volcanic rocks can be modified 400 by a number of syn- and post-eruption processes such as degassing, subaerial aqueous alteration, 401 submarine hydrothermal alteration and submarine precipitation of Fe-Mn minerals on sample 
402 surfaces. In addition, assimilation of wall rock and fractional crystallization prior to eruption

403 could also alter the $\mathrm{Tl}$ budget of the original magma if the $\mathrm{Tl}$ concentrations and/or isotope

404 compositions of wall rock and crystallizing phases were different from that of the original

405 magma. In the following sections we discuss the potential for these processes to have affected

406 our $\mathrm{Tl}$ isotopic data for lavas from the Aleutian arc in order to assess how much $\mathrm{Tl}$ isotope

407 variation can be directly linked to inputs from the subducted slab.

408

409

410 Lavas erupted under submarine conditions are easily contaminated with Tl either associated

411 with clay minerals that form during alteration of the lava (Jochum and Verma, 1996) or due to

412 precipitation of Fe-Mn oxyhydroxides that form ubiquitously in oxic seawater (Nielsen and

413 Rehkämper, 2011). As outlined in section 2, both these components are characterized by very

414 strong $\mathrm{Tl}$ enrichments compared with those found in mantle derived melts as well as substantial

$415 \mathrm{Tl}$ isotope fractionation (Coggon et al., 2014; Nielsen et al., 2006c; Rehkämper et al., 2004).

416 Thus, even minute amounts of these contaminants may completely alter the Tl concentration and

417 isotope composition of a given sample. In order to eliminate these sources of contamination, we

418 analyzed only rock chips of dredge samples (not powders), which were prepared as described

419 above to eliminate possible effects of seawater-rock interaction. The results of these analyses

420 reveal $\mathrm{Tl}$ isotope and concentration patterns for a few samples that could reflect alteration or Fe-

421 Mn mineral contamination. Additional tests were, therefore, conducted on a subset of the

422 samples to further investigate if contamination was significant (Table 3). These tests involved

423 leaching two separate aliquots of chips in $1 \mathrm{M} \mathrm{HCl}$ and $6 \mathrm{M} \mathrm{HCl}$, respectively, during

424 ultrasonication. The results of these tests confirm that one sample (TN182_07_002) had clearly 
425 been affected by minor Fe-Mn mineral contamination. This assessment was confirmed by 426 analysis of both an untreated aliquot of the sample as well as the $1 \mathrm{M} \mathrm{HCl} \mathrm{leachate,} \mathrm{both} \mathrm{of} \mathrm{which}$ 427 showed heavy Tl isotope compositions as would be expected for Fe-Mn minerals (Nielsen et al., 428 2013; Peacock and Moon, 2012; Rehkämper et al., 2002). It is notable that even though the 1M $429 \mathrm{HCl}$ leachate contained only very small amounts of $\mathrm{Tl}$ (2 ng per gram of sample) the exceedingly 430 heavy $\mathrm{Tl}$ isotope composition of the leachate $\left(\varepsilon^{205} \mathrm{Tl}=+9.8\right)$, which is consistent with values

431 found in Fe-Mn crusts (Nielsen et al., 2011; Nielsen et al., 2009; Rehkämper et al., 2002), 432 approximately accounts for the small isotopic shift observed in the unleached samples. The 433 uncontaminated $\mathrm{Tl}$ isotope composition of the sample is, therefore, best represented by the 434 leached aliquots both of which display identical values of $\varepsilon^{205} \mathrm{Tl}=-1.8$. We are confident that the 435 leaching process has not induced notable $\mathrm{Tl}$ loss or isotope fractionation in sample 436 TN182_07_002 because leaching of an uncontaminated sample (TN182_07_009) yielded a result 437 identical to the untreated sample aliquot (Table 3).

\subsubsection{Degassing}

440 Degassing should be expressed as a loss of $\mathrm{Tl}$ potentially associated with kinetic isotope 441 fractionation whereby the light $\mathrm{Tl}$ isotope would preferentially be lost. Thallium isotope 442 measurements of volcanic fumaroles did not find any systematic enrichment in ${ }^{203} \mathrm{Tl}$ (Baker et 443 al., 2009), suggesting that kinetic Tl isotope fractionation during degassing might be limited. 444 However, these effects have never been investigated for actual rocks, which makes it difficult to 445 predict the magnitude of $\mathrm{Tl}$ isotope and concentration effects from degassing.

446 Given that Tl partitioning during mantle melting is similar to that of Ce (Nielsen et al., 447 2014), it could be inferred that unusually high $\mathrm{Ce} / \mathrm{Tl}$ ratios coupled with heavy $\mathrm{Tl}$ isotope 
448 compositions might be indicative of significant degassing. However, because $\mathrm{Ce} / \mathrm{Tl}$ in both 449 sediments and $\mathrm{AOC}(\mathrm{Ce} / \mathrm{Tl} \sim 100-400)$ is much lower than the upper mantle $(\mathrm{Ce} / \mathrm{Tl} \sim 1100$, 450 (Nielsen et al., 2014)) variations in $\mathrm{Ce} / \mathrm{Tl}$ are not necessarily due to degassing unless $\mathrm{Ce} / \mathrm{Tl}$ 451 significantly exceeds the mantle value. Except for three samples, all Aleutian lavas display Ce/Tl 452 ratios significantly lower than the upper mantle (Fig. 3). In addition all samples fall within the 453 field expected for mixing between the mantle and sediments or AOC (Fig. 3), which suggests 454 that degassing did not significantly affect $\mathrm{Tl}$ concentrations or isotopes in the majority of the 455 samples studied here.

456 Of the three samples that display significantly higher $\mathrm{Ce} / \mathrm{Tl}$ than sediments and AOC, one 457 (SAR-17) displays $\mathrm{Ce} / \mathrm{Tl}$ and $\varepsilon^{205} \mathrm{Tl}$ within error of the upper mantle, which could be consistent 458 with a melt largely unmodified by addition of slab material. However, $\mathrm{Pb}$ isotope ratios in SAR45917 and other samples from this volcano are much more radiogenic (Table 2) than the depleted 460 MORB mantle (Workman and Hart, 2005), which likely reflects the influence of terrigenous 461 sediments (Kay et al., 1978). Alternatively, the low $\mathrm{Tl}$ content of this sample may reflect 462 degassing from a lava that either 1) had a starting $\mathrm{Tl}$ isotope composition significantly lighter 463 than the normal mantle or 2) did not register any significant $\mathrm{Tl}$ isotope fractionation during 464 degassing. The latter interpretation would be consistent with the data of Baker et al. (2009), 465 which showed no systematic enrichment in ${ }^{203} \mathrm{Tl}$ for volcanic fumaroles.

466 The second sample (TN182_07_005) with Ce/Tl similar to the upper mantle is characterized 467 by $\varepsilon^{205} \mathrm{Tl}$ significantly heavier than the upper mantle (Table 3), which is consistent with 468 degassing coupled with kinetic $\mathrm{Tl}$ isotope fractionation. This conclusion is supported by the 469 chemical compositions of samples TN182_07_009 and TN182_07_005, which were collected in 470 close proximity to one another, being almost identical for all elements except $\mathrm{Tl}$ concentrations 
471 and isotopes. It is unclear exactly why $\mathrm{Tl}$ isotopes are significantly different for these two

472 samples, but, given the anomalous Tl isotope composition, we infer that TN182_07_005 was

473 likely degassed and does not reflect the primary $\mathrm{Tl}$ isotope systematics of the original lava.

474 Therefore, we will not consider it further in our discussion of slab-mantle interactions in the 475 Aleutian arc and it has not been included in any figure except Figure 2.

476 The last sample to display $\mathrm{Ce} / \mathrm{Tl}$ higher than the upper mantle is the Miocene adakite lava 477 from Mt. Moffett (ADK53), which could indicate significant Tl degassing. However, the Tl 478 isotope composition of ADK53 is not enriched in ${ }^{205} \mathrm{Tl}$ (Table 2), as might be expected from 479 kinetic isotope fractionation. In addition, this sample has, based on its high $\mathrm{Sr} / \mathrm{Y}$ and 480 unradiogenic $\mathrm{Sr}$ and $\mathrm{Pb}$ isotope ratios, been proposed as a possible melt derived from eclogitized 481 oceanic crust (Kay, 1978). Bulk Tl and Ce partition coefficients during melting of eclogite are 482 unlikely to be identical to those found for mantle melting and therefore it is possible that $\mathrm{Ce} / \mathrm{Tl}$ 483 could be significantly altered during eclogite melting. Thallium partitions into sulfide (Kiseeva 484 and Wood, 2013; Nielsen et al., 2014) and probably phengite (Prytulak et al., 2013) while Ce 485 may be accommodated by allanite and/or epidote (Carter et al., 2015; Hermann, 2002). The 486 relative abundances of these minerals will have a strong control on melt $\mathrm{Ce} / \mathrm{Tl}$ especially at low 487 degrees of melting where these phases potentially could be in the residue. However, given the 488 lack of experimental data on $\mathrm{Tl}$ partitioning at relevant conditions it is currently not possible to 489 constrain the effect on $\mathrm{Ce} / \mathrm{Tl}$ during eclogite melting. Therefore, it we cannot conclusively 490 distinguish between degassing or source mineralogy as the cause of the high Ce/Tl observed in $491 \quad$ ADK53.

492 For the remaining samples in this study we do not find any chemical or isotopic indications 493 of significant degassing. If $\mathrm{Tl}$ degassing played a role in the $\mathrm{Tl}$ budgets of the lavas investigated 
494 here, then the effects are too small to quantify and most likely smaller than the Tl elemental and

495 isotopic signatures imposed by addition of subduction components.

497 6.1.3. Subaerial aqueous alteration

498 Subaerial lavas are often observed to preferentially lose alkali metals during aqueous

499 alteration from meteoric water (Schiano et al., 1993). This effect is most likely due to the high

500 solubility of these metals in aqueous solution and given the geochemical similarity between $\mathrm{Tl}$

501 and the alkali metals (i.e. ionic charge and radius as well as high aqueous solubility) one might

502 expect subaerial alteration to be accompanied by significant $\mathrm{Tl}$ losses that would lead to high

$503 \mathrm{Ce} / \mathrm{Tl}$ ratios. These losses, however, would likely not be associated with $\mathrm{Tl}$ isotope fractionation

504 because weathering has been shown to cause negligible $\mathrm{Tl}$ isotope fractionation (Nielsen et al., 505 2005).

506 High $\mathrm{Ce} / \mathrm{Tl}$ ratios produced by subaerial weathering should be coupled with significant 507 losses of alkali metals. Here we investigate this using $\mathrm{Th} / \mathrm{Rb}$ as these two elements partition 508 similarly in igneous processes while Th is highly insoluble in aqueous solution. Thus, high $509 \mathrm{Th} / \mathrm{Rb}$ coupled with high $\mathrm{Ce} / \mathrm{Tl}$ might indicate subaerial alteration. Figure 4 shows that only 510 sample ADK53 has a clear signature that could be interpreted as subaerial alteration. Some 511 alteration of ADK53 is also reasonable given that it is Miocene in age. All other samples 512 investigated here are relatively recent, fresh lava flows that are unlikely to have experienced 513 significant alteration. It should be noted that, while the trace element systematics of mobile 514 elements like $\mathrm{K}, \mathrm{Rb}, \mathrm{Cs}$ and $\mathrm{Tl}$ may have been perturbed in ADK53, there is no indication that 515 the original isotope compositions (radiogenic or $\mathrm{Tl}$ ) of this lava have been reset by post-eruption 
516 processes. We, therefore, use the isotopic characteristics of ADK53 in our discussion of

517 subduction processes in the Aleutian arc, but omit trace element ratios from consideration.

\section{6.1.4. Assimilation and fractional crystallization}

520 Fractional crystallization in itself is not likely to alter the Tl isotope composition of magma.

521 First, $\mathrm{Tl}$ is likely very incompatible in the major crystallizing phases like olivine, clinopyroxene 522 and plagioclase (Adam and Green, 2006; Nielsen et al., 2014). Second, lavas from Korovin

523 volcano (Atka Island) also support the lack of $\mathrm{Tl}$ isotope fractionation with magmatic

524 differentiation. These Korovin lavas display patterns broadly consistent with evolution by 525 fractional crystallization from basalt to high-silica andesite (Fig 5). Thallium is enriched in the 526 more evolved lavas and the progressive $\mathrm{Tl}$ enrichment is not accompanied by any systematic $\mathrm{Tl}$ 527 isotope change (Table 2), which confirms that fractional crystallization does not impart any 528 detectable $\mathrm{Tl}$ isotope fractionation. The constancy of $\mathrm{Tl}$ isotopes for the more evolved samples 529 also shows that any assimilation that might have occurred during fractional crystallization of the 530 Korovin samples did not cause a notable change in $\mathrm{Tl}$ isotopes.

531 Even though fractional crystallization and assimilation appears to have a limited effect on $\mathrm{Tl}$ 532 isotopes, we still choose to exclude samples from the Eastern and Central Aleutian Islands that 533 bear evidence of magmatic evolution ( $>55 \mathrm{wt} \% \mathrm{SiO}_{2},<3 \% \mathrm{MgO}$ and $\left.\mathrm{Mg \#}<45\right)$ in order to 534 remove any doubt that some $\mathrm{Tl}$ isotope variation could be caused by these processes. This step 535 removes the three most evolved Korovin samples from consideration as well as one from

536 Westdahl (SAR-4). It should be noted that all of the excluded samples display $\varepsilon^{205} \mathrm{Tl} \sim-2$ (Table 537 2), which could indicate that assimilation of the arc crust tends to add $\mathrm{Tl}$ with an isotope 
538 composition that is similar to continental crust. Hence, assimilation may possibly attenuate the $\mathrm{Tl}$

539 isotope variation of arc lavas.

540 One sample from the Western Aleutians (TN182_08_003) is unusually enriched in Tl 541 compared with all other Aleutian samples (subaerial or submarine) investigated here. The sample 542 displays $\mathrm{Ce} / \mathrm{Tl} \sim 35$, a factor of about 4 lower than any other sample in this study. It also has the

543 lightest $\mathrm{Tl}$ isotope composition measured for the Aleutians $\left(\varepsilon^{205} \mathrm{Tl}=-9.3\right)$ and the leaching 544 experiments confirmed that this value was unlikely to be caused by seawater alteration (Table 3).

545 Inspection of the sample in thin section did not reveal any alteration minerals. However, the 546 sample contains abundant amphibole phenocrysts many of which have resorbed textures 547 indicating that amphibole was first crystallized and then started re-dissolving back into the melt 548 (Yogodzinski et al., 2015). TN182_08_003 is the only basalt sample recovered from the Western 549 Aleutians, which exhibits this texture, which may indicate that the liquid line of decent was 550 interrupted potentially by assimilation of wall rock. If the magma chamber that hosted the lava 551 prior to eruption was relatively shallow in the upper few $\mathrm{km}$ of the crust then the wall rock could 552 be composed of low-temperature altered volcanic rocks, which are known to carry high $\mathrm{Tl}$ 553 concentrations and very light Tl isotope compositions (Coggon et al., 2014; Nielsen et al., 554 2006c). Such assimilation processes would likely not affect radiogenic isotope systems like Pb, $555 \mathrm{Nd}$ and $\mathrm{Sr}$ because low-temperature AOC is not significantly enriched in these elements 556 compared with fresh basalt and does not possess radiogenic isotope compositions that deviate 557 substantially from fresh MORB and thereby also the compositions of the primary magma. 558 Strontium isotope ratios of basaltic oceanic crust do become more radiogenic when interacting 559 with seawater, but the vast majority of $\mathrm{Sr}$ isotope data for AOC in the literature display ${ }^{87} \mathrm{Sr} /{ }^{86} \mathrm{Sr}$ 560 0.703-0.705 (Staudigel et al., 1995; Teagle et al., 2003), which is only slightly different to 
561 TN182_08_003 that exhibits ${ }^{87} \mathrm{Sr} /{ }^{86} \mathrm{Sr}=0.7033$. We, therefore, conclude that this sample has

562 been contaminated by assimilation of low-temperature AOC at relatively shallow crustal depths

563 prior to eruption and do not consider it further in our discussion of Aleutian sub-arc mantle

564 processes.

565

\subsection{Sediment controls $\mathrm{Tl}$ isotope variation in the Central and Eastern Aleutian Islands}

Excluding the sample that shows evidence of degassing (SAR-17) as well as the more evolved lavas (SAR-4, and three Korovin lavas) does not change the range of $\mathrm{Tl}$ isotope compositions recorded in the Eastern and Central Aleutian samples $\left(\varepsilon^{205} \mathrm{Tl}=-3.8\right.$ to +2.6$)$. We interpret these data as representative of the $\mathrm{Tl}$ isotope variation in the mantle sources of the

571 Aleutian lavas investigated here. Only one sample (Kanaga S489, $\varepsilon^{205} \mathrm{Tl}=-3.8$ ) is lighter than

572 the normal mantle value of $\varepsilon^{205} \mathrm{Tl}=-2 \pm 0.5$ (Nielsen et al., 2007; Nielsen et al., 2006b; Nielsen

573 et al., 2006c) with 13 of the remaining 18 samples exhibiting $\mathrm{Tl}$ isotope compositions

574 significantly heavier than normal mantle. The generally heavy $\mathrm{Tl}$ isotope compositions of the 575 lavas are similar to the $\mathrm{Tl}$ isotope variation in the sediments outboard of the Aleutian arc (Fig. 2), 576 which clearly implicates sediments as a significant source of $\mathrm{Tl}$ in the Aleutians. In detail, 577 however, there are some important systematic along-arc changes in $\mathrm{Tl}$ isotopes that provide clues 578 to processes taking place in the sub-arc mantle.

$579 \quad$ As has been noted previously (Kay and Kay, 1994; Sun, 1980; Yogodzinski et al., 2011), 580 the composition of sediment subducted underneath the Aleutian arc is expected to change from 581 continental detrital in the east as represented by DSDP Site 178 toward compositions with a 582 higher proportion of abyssal clay in the Central Aleutians. Here we have obtained the first data 583 from a drill hole outboard of the Central Aleutians (ODP Hole 886C), which confirms that 
584 pelagic clays enriched in trace elements like $\mathrm{Nd}, \mathrm{Pb}$ and $\mathrm{Tl}$ are common at this location. 585 Thallium isotope compositions of sediments in DSDP Sites 178 and 183 and ODP Hole 886C 586 conform to the expected relationship whereby sediments more proximal to the continent display $587 \varepsilon^{205} \mathrm{Tl} \sim-2$, with increasingly heavy $\mathrm{Tl}$ isotope compositions as sediment deposition rates decline 588 and therefore contain higher concentrations of authigenic Fe and Mn oxides (Figs. 2 and 6).

589 The clear shift in $\mathrm{Tl}$ isotope composition of sediments from $\varepsilon^{205} \mathrm{Tl} \sim-2$ outboard of the 590 Eastern Aleutians to $\varepsilon^{205} \mathrm{Tl}>0$ outboard of the Central Aleutians is mirrored by the average $\mathrm{Tl}$ 591 isotope compositions of lavas in these locations (Figs. 7 and 8). Although each island appears to 592 preserve some $\mathrm{Tl}$ isotope variation outside of analytical uncertainty (Figs. 7 and 8), on average, 593 islands in the Central Aleutians exhibit heavier Tl isotope compositions than do the islands in the 594 Eastern Aleutians. The relationship between $\mathrm{Tl}$ isotope compositions in subducted sediments and 595 the extruded lavas indicates that sediment inputs are the main control on $\mathrm{Tl}$ isotope compositions 596 of lavas in the Aleutians east of Kanaga Island. This interpretation is corroborated by the inverse 597 correlation observed between $\mathrm{Pb}$ and $\mathrm{Tl}$ isotopes for the Central and Eastern Aleutian lavas (Fig. 598 7). It is important to note that this inverse correlation does not reflect two-component mixing, but 599 that each point lies on an individual mixing line between the mantle wedge and a unique pelagic600 detrital mix.

601 However, the observed trend is generally consistent with the $\mathrm{Pb}$ isotopes observed for 602 pelagic clays at ODP $886 \mathrm{C}$ that are, on average, less radiogenic than the detrital-dominated 603 sediments at DSDP Sites 178 and 183. Mixing lines between the sub-arc mantle and bulk detrital 604 and pelagic sediments show that the quantity of sediment added from the slab to the sub-arc 605 mantle decreases systematically from the Eastern to the Central Aleutians, which is consistent 
with the previously inferred subducted sediment flux along the Aleutian arc (Kay and Kay, 1994;

607 Kelemen et al., 2003).

This trend is also reproduced in plots of Sr-Tl and Nd-Tl isotopes (Fig. 8), which shows that

609 all four elements are likely dominated by sediment fluxes from the slab. The amount of bulk

610 sediment required to account for the observed $\mathrm{Nd}, \mathrm{Pb}, \mathrm{Sr}$ and $\mathrm{Tl}$ isotope variations are

611 consistently $\sim 0.6-1 \%$ by weight in the east, while mixing relationships in the Central Aleutians

612 using $\mathrm{Nd},{ }^{206} \mathrm{~Pb} /{ }^{204} \mathrm{~Pb}, \mathrm{Sr}$ and $\mathrm{Tl}$ isotopes are consistent with $\sim 0.2-0.6 \%$ by weight sediment

613 addition, which is in reasonable agreement with previous work that inferred up to 2 weight $\%$

614 sediment in the mantle sources of the Aleutian Islands (Kay, 1980; Kay and Kay, 1988; Kay et

615 al., 1978; Kelemen et al., 2003; Yogodzinski et al., 2011). Interestingly, bulk sediment mixing

616 using ${ }^{207} \mathrm{~Pb} /{ }^{204} \mathrm{~Pb}$ and ${ }^{208} \mathrm{~Pb} /{ }^{204} \mathrm{~Pb}$ (Figs. 7b and $\left.7 \mathrm{c}\right)$ predict significantly smaller $(<0.2 \%$ by

617 weight) pelagic sediment fractions in the Central Aleutians than do all other isotope ratios.

618 This consistent offset might be explained by addition of a third component with 619 unradiogenic ${ }^{207} \mathrm{~Pb} /{ }^{204} \mathrm{~Pb}$ and ${ }^{208} \mathrm{~Pb} /{ }^{204} \mathrm{~Pb}$ such as a fluid from AOC (Miller et al., 1994). To 620 maintain the consistent mixing relationships illustrated in Fig. 8, such a fluid would have to be 621 highly enriched in $\mathrm{Pb}$ compared with $\mathrm{Nd}, \mathrm{Sr}$ and $\mathrm{Tl}$. In addition, the ${ }^{206} \mathrm{~Pb} /{ }^{204} \mathrm{~Pb}$ of the fluid could 622 not be significantly less radiogenic than $18.6-18.7$ in order to preserve the $\sim 0.4 \%$ pelagic 623 sediment produced by the mixing relationship in Figure 7a. Alternatively, it is also possible that 624 the average subducted sediment outboard of the Central Aleutians is more affected by the type of 625 highly enriched pelagic sediment represented by $886 \mathrm{C}-8 \mathrm{H}-4$ 58-60cm (Table 4), which is 626 characterized by highly unradiogenic ${ }^{207} \mathrm{~Pb} /{ }^{204} \mathrm{~Pb}$ and ${ }^{208} \mathrm{~Pb} /{ }^{204} \mathrm{~Pb}$, whereas ${ }^{206} \mathrm{~Pb} /{ }^{204} \mathrm{~Pb}$ is only 627 slightly less radiogenic than most of the other pelagic sediment samples from ODP Hole 886C. 628 Hence, if material similar to sample $8 \mathrm{H}-458-60 \mathrm{~cm}$ represents close to $60 \%$ of the subducted 
629 sediment $\mathrm{Pb}$ budget the bulk subducted sediment would be characterized by ${ }^{207} \mathrm{~Pb} /{ }^{204} \mathrm{~Pb} \sim 15.57$

630 and ${ }^{208} \mathrm{~Pb} /{ }^{204} \mathrm{~Pb} \sim 38.3$, which would yield mixing relationships requiring $\sim 0.4 \%$ bulk sediment

631 like those observed for $\mathrm{Nd},{ }^{206} \mathrm{~Pb} /{ }^{204} \mathrm{~Pb}, \mathrm{Sr}$ and $\mathrm{Tl}$ isotopes. The present fraction of $\mathrm{Pb}$ in ODP

632 Hole $886 \mathrm{C}$ contributed from the basal pelagic sediment is $\sim 35 \%$, which is based on visual

633 inspection of core barrel photographs (Rea et al., 1993). Although this method of estimating

634 average sediment core compositions is the best available (short of conducting hundreds of

635 individual sediment analyses throughout a core), it carries significant uncertainties for elements

636 such as $\mathrm{Pb}, \mathrm{Tl}, \mathrm{La}$ and $\mathrm{Nd}$ that display almost two orders of magnitude concentration variations

637 in individual sediment horizons. Hence, if the sediment thickness and/or average concentration

638 of certain sediment horizons have been under- or overestimated this could lead to large changes

639 in the whole-core average composition.

640 The similarity in the required sediment component based on $\mathrm{Sr}, \mathrm{Nd}, \mathrm{Pb}$ and $\mathrm{Tl}$ isotopes

641 suggests that initial mixing between sediment and mantle does not strongly fractionate these four

642 trace elements. However, it is well documented that Aleutian lavas (and arc lavas in general)

643 display highly fractionated $\mathrm{Sr} / \mathrm{Nd}$ and $\mathrm{Pb} / \mathrm{Nd}$ compared with all the bulk input components that

644 enter the subduction zone (Class et al., 2000; Miller et al., 1994). Therefore, there must be one or

645 more processes occurring within the subduction zone that are capable of fractionating trace

646 elements. Combining the evidence from isotope-isotope diagrams and the ubiquitous trace

647 element fractionation in arcs would, therefore, suggest that mixing and trace element

648 fractionation occur in two separate steps. The elemental fractionations of $\mathrm{Sr} / \mathrm{Nd}, \mathrm{Ce} / \mathrm{Pb}, \mathrm{Th} / \mathrm{Nd}$

649 and others are often inferred to originate from melting or dehydration of slab sediment and/or

650 altered oceanic crust with phases such as allanite, monazite, apatite, phengite, biotite, lawsonite

651 or sulfide in the residue (Hermann and Rubatto, 2009; Johnson and Plank, 1999; Prytulak et al., 
652 2013). These accessory phases could produce large variations in the transport efficiency of Sr,

$653 \mathrm{Nd}, \mathrm{Pb}$ and $\mathrm{Tl}$, because of the strong compatibility of $\mathrm{Nd}$ in allanite and monazite, $\mathrm{Pb}$ in sulfide

654 and apatite, and $\mathrm{Tl}$ in sulfide, biotite and phengite. Thus, sediment melts released from the slab

655 into the mantle wedge are likely characterized by fractionated $\mathrm{Sr} / \mathrm{Nd}, \mathrm{Pb} / \mathrm{Tl}, \mathrm{Sr} / \mathrm{Tl}$ and $\mathrm{Nd} / \mathrm{Tl}$

656 ratios that would cause strong curvature in the isotope mixing diagrams (Figs. 7 and 8) that is not

657 compatible with the consistent bulk mixing relationships observed.

658 Of the four isotope systems considered here, reliable experimental data for element 659 partitioning during sediment melting only exists for $\mathrm{Sr}$ and Nd (Hermann and Rubatto, 2009;

660 Johnson and Plank, 1999; Skora and Blundy, 2010). These data show that over a range of 661 temperatures $\left(600-1050^{\circ} \mathrm{C}\right)$ and sediment compositions, $\mathrm{Nd}$ is preferentially retained in the 662 sediment residue (notably by monazite), while Sr is uniformly released into the melt phase. On 663 average, experiments in the temperature range from $700-900^{\circ} \mathrm{C}$ show that $\mathrm{Sr}$ is about 20 times 664 less compatible than $\mathrm{Nd}$ during sediment melting, which results in high $\mathrm{Sr} / \mathrm{Nd}$ ratios in the 665 sediment melts. A potential problem with these experiments is that they were all doped with 666 relatively large amounts of $\mathrm{Nd}$ and other REE, which may have stabilized excess abundances of 667 monazite because REE are a main constituent of the mineral. The Nd partition coefficients 668 presented in these studies may, therefore, be higher than for undoped compositions. Irrespective 669 of the absolute partition coefficients, sediment melts are expected to be characterized by higher $670 \mathrm{Sr} / \mathrm{Nd}$ ratios than the bulk sediment, which generates significantly different mixing relationships 671 between mantle and sediment melts compared to bulk sediment. Figure 9 shows the effect of the 672 different $\mathrm{Nd} / \mathrm{Sr}$ ratios in bulk sediment and sediment melts generated by $20 \%$ melting of the 673 subducted sediment components in the Eastern and Central Aleutians when using the 674 experimental data currently available in the literature. It is evident that none of the lavas studied 
675 here nor those of other published lavas from the Central and Eastern Aleutians fall within the

676 sediment melt field. Larger degrees of sediment melting (Skora and Blundy, 2010) will move the

677 sediment melt field closer to the bulk sediment field, but even $40 \%$ sediment melting will only

678 move a few of the samples into the sediment melt field and then only close to the mixing line

679 with ODP $886 \mathrm{C}$ sediment melts.

680 On the other hand, if monazite abundances for un-doped sediment compositions are lower 681 than doped experiments suggest, then it is likely that degrees of sediment melting around 20$68240 \%$ will significantly attenuate the $\mathrm{Sr} / \mathrm{Nd}$ fractionation of the sediment melt because the 683 accessory phases responsible for the elemental fractionation are almost or entirely melted out 684 (Hermann and Rubatto, 2009). In this case, sediment melts will fail to produce the high $\mathrm{Sr} / \mathrm{Nd}$ 685 ratios (and likely also other trace element ratios that might be governed by residual accessory 686 phases) observed in Aleutian lavas and therefore processes subsequent to mantle-sediment melt 687 mixing would be needed to fractionate trace element ratios like $\mathrm{Sr} / \mathrm{Nd}, \mathrm{Ce} / \mathrm{Pb}, \mathrm{Cs} / \mathrm{Tl}$ and $\mathrm{Th} / \mathrm{Nd}$.

688 Bulk sediment transfer from slab to mantle wedge could be consistent with recent models of 689 sediment transport from the slab to the mantle wedge whereby either pure sediment (Behn et al., 690 2011) or mélange diapirs (Marschall and Schumacher, 2012) are the primary mode of adding 691 sediments and/or AOC to the source regions of arc lavas. Mélange formation at the slab-mantle 692 interface, which based on field studies is common in subduction zones (Bebout, 1991; King et 693 al., 2003), represents a mixture between slab material (both sediments and AOC) and the mantle 694 wedge. Therefore, average mélange material is expected to plot along bulk mixing lines between 695 mantle and sediment/AOC slab components, similar to what we observe in Figures 7-9.

696 It is important to note that the isotope-isotope plots (Figs. 7-9) only provide information 697 about the elemental ratios (e.g. $\mathrm{Sr} / \mathrm{Nd}, \mathrm{Tl} / \mathrm{Sr}, \mathrm{Tl} / \mathrm{Nd}, \mathrm{Tl} / \mathrm{Pb}$ ) at the time when the components 
mixed. Subsequent trace element fractionation would not be detected in these plots. In other

699 words, models that invoke bulk mixing between mantle and sediment/AOC require that the

700 strong fractionation of trace elements observed in arc lavas, including $\mathrm{Sr} / \mathrm{Nd}, \mathrm{Ce} / \mathrm{Pb}$ and $\mathrm{Nd} / \mathrm{Th}$,

701 must then occur upstream of the mixing process rather than prior to. Melting of mélange diapirs

702 in the mantle wedge (Marschall and Schumacher, 2012) is a potential means of fractionating

703 trace elements if melting residuals at high temperatures (likely $>1100^{\circ} \mathrm{C}$ ) contains the residual

704 phases that may produce the required trace element fractionations. Future experiments and

705 studies of mélange material at subduction zone conditions will need to investigate the viability of

706 these processes in more detail.

707

\subsection{Thallium isotope signature of slab melts from altered oceanic crust}

709

The $\mathrm{Tl}$ isotope ratios determined for samples from the Western Aleutians are systematically

710 different from those observed in the Central and Eastern Aleutian Islands. When the two samples

711 affected by assimilation and degassing (TN182_07_005 and TN182_08_003) are excluded, all

712 samples except two fall within a limited range of $\varepsilon^{205} \mathrm{Tl}=-1.5$ to -3.4 (Table 3). Even though this

713 range only represents about four times our long-term reproducibility there is a suggestion that $\mathrm{Tl}$

714 isotopes correlate with both $\mathrm{Sr}$ and $\mathrm{Pb}$ isotopes, whereby the least radiogenic $\mathrm{Sr}$ and $\mathrm{Pb}$ isotope

715 compositions are characterized by $\varepsilon^{205} \mathrm{Tl} \sim-3.5$ (Figs. 7 and 8). We also find that the Miocene

716 sample from Adak Island, ADK53, falls close to these trends, suggesting that the Western

717 Aleutian lavas were influenced by the same component as ADK53. There is strong evidence that

718 the Western Aleutian lavas as well as ADK53 sample a distinct component of eclogite slab melt

719 (Kay, 1978; Yogodzinski et al., 2015; Yogodzinski et al., 1995) that is characterized by high

$720 \mathrm{Sr} / \mathrm{Y}$ and $\mathrm{Dy} / \mathrm{Yb}$ coupled with unradiogenic $\mathrm{Pb}$ and $\mathrm{Sr}$ isotope compositions. This eclogite melt 
721 likely originates from subducted basaltic oceanic crust that was transformed at depth to eclogite.

722 Conversely, the lack of heavy $\mathrm{Tl}$ isotope compositions in the Western Aleutians indicate that

723 sediments do not play a major role for the $\mathrm{Tl}$ mass balance of these lavas. This observation is

724 consistent with the strongly attenuated sediment flux underneath the Western Aleutians

725 (Kelemen et al., 2003; Yogodzinski et al., 1994) as well as radiogenic isotope compositions of

726 Western Aleutian samples, which have among the least radiogenic $\mathrm{Pb}$ and most radiogenic $\mathrm{Nd}$ in

727 the Aleutians. Nonetheless, plots of $\mathrm{Pb}-\mathrm{Pb}$ and $\mathrm{Nd}-\mathrm{Pb}$ isotopes as well as $\mathrm{Ce} / \mathrm{Pb}$ significantly

728 lower than normal mantle imply that minor sediment or fluid components are present in Western

729 Aleutian samples (Yogodzinski et al., 2015). Therefore, simple mixing of melts from eclogitized

730 oceanic crust and the mantle wedge cannot account for the petrogenesis of most Western

731 Aleutian volcanics.

732 Thallium concentrations and isotope compositions of oceanic crust display distinct and 733 systematic variations with crustal depth (Nielsen et al., 2006c). In particular, the upper volcanic

734 zone is enriched in $\mathrm{Tl}$ with distinct $\varepsilon^{205} \mathrm{Tl}<-2$. The sheeted dike complex, lower crustal gabbros

735 and ultramafic cumulates, however, are likely very depleted in $\mathrm{Tl}$ and exhibit $\varepsilon^{205} \mathrm{Tl} \sim-2$, which

736 is indistinguishable from the MORB mantle (Nielsen et al., 2006c). In the Western Aleutian

737 lavas, the proposed eclogite melt endmember is characterized by the lightest $\mathrm{Tl}$ isotope

738 compositions suggesting that at least part of the eclogite source region formed from the volcanic

739 zone of the subducted basaltic crust. This inference is also supported by the relatively high $\mathrm{Tl}$

740 concentrations for the putative eclogite component of up to $150 \mathrm{ng} / \mathrm{g}$ (Table 3), which would

741 imply a source region containing $\mathrm{Tl}$ concentrations significantly in excess of the $\sim 1 \mathrm{ng} / \mathrm{g} \mathrm{Tl}$

742 observed for the sheeted dike complex (Nielsen et al., 2006c). 
One lava from Kanaga Island (S489) is the only sample from the main Aleutian Islands in

744 this study that exhibits $\varepsilon^{205} \mathrm{Tl}<-2$, which could be indicative of influence from low-temperature

745 altered oceanic crust. There is no indication based on $\mathrm{Sr} / \mathrm{Y}, \mathrm{Dy} / \mathrm{Yb}$ or radiogenic isotope ratios

746 that a significant component derived from slab melting has influenced this sample. However,

747 given the generally attenuated sediment flux needed to account for radiogenic isotope data from

748 the Central Aleutians compared to the Eastern Aleutians (Figs. 7 and 8), it is possible that some

749 volcanoes in the Central Aleutians become more dominated by inputs from dehydrated altered

750 oceanic crust. Such an interpretation would be consistent with the greater range in Tl isotopes

751 observed for Kanaga Island, which could reflect that the relative contributions of $\mathrm{Tl}$ from

752 sediments and altered oceanic crust are highly variable when the subducted sediment flux

753 becomes sufficiently small.

\subsection{Possible contributions from oceanic crust dehydration}

756 Sediments have been widely implicated as the primary component that causes radiogenic $\mathrm{Pb}$,

757 Sr and Nd isotope variation in the Eastern and Central Aleutians (Kay and Kay, 1988; Kay et al.,

758 1978; Kelemen et al., 2003), which is clearly supported by our new Tl isotope data (Figs. 7 and

759 8). However, fluids sourced from dehydrating oceanic crust as well as melts from eclogitized

760 oceanic crust may also contribute to lavas in the Central and Eastern Aleutian Islands (Jicha et

761 al., 2004; Miller et al., 1994; Singer et al., 2007; Yogodzinski et al., 2015; Yogodzinski et al.,

762 1995). For example, several studies have suggested that a fluid extracted from AOC can account

763 for the excess Sr in Aleutian lavas (Class et al., 2000; Jicha et al., 2004; Singer et al., 2007). This

764 process is clearly a reasonable way to explain the trace element fractionation of several key trace

765 elements (notably the high $\mathrm{Sr} / \mathrm{Nd}, \mathrm{Pb} / \mathrm{Ce}$ and $\mathrm{B} / \mathrm{La}$ ). However, addition of an AOC component 
766 would cause $\mathrm{Sr}$ isotopes to become slightly more radiogenic (assuming ${ }^{87} \mathrm{Sr} /{ }^{86} \mathrm{Sr} \sim 0.704$ in the 767 upper $\sim 600$ meters of the oceanic crust (Staudigel et al., 1995; Teagle et al., 2003)) whereas Nd 768 would be largely unaffected due to the low solubility of $\mathrm{Nd}$ in the fluid phase (Kessel et al., 769 2005). Adding this 'fluid AOC' component to the sediment melt would move the sediment melt770 mantle mixing lines in Figure 9 upwards and therefore even further away from the sediment melt

771 field. On the other hand, if 'fluid AOC' Sr were derived from throughout the oceanic crust (with $\left.772 \mathrm{MORB}{ }^{87} \mathrm{Sr} /{ }^{86} \mathrm{Sr} \sim 0.7025\right)$ and this fluid exhibited elevated $\mathrm{Sr} / \mathrm{Nd}$ similar to low degree $(<20 \%)$ 773 sediment melts, then a mixing line could be produced that is indistinguishable from mantle-bulk 774 sediment mixing, and would intersect the Aleutian arc data. Hence, low degree $(<20 \%)$ sediment 775 melts are able to explain the $\mathrm{Sr}-\mathrm{Nd}$ isotope data from the Aleutian arc if they were mixed with 776 AOC fluids characterized by MORB isotope compositions and $\mathrm{Sr} / \mathrm{Nd}$ ratios similar to the 777 sediment melt. However, this scenario would require that less than $15 \%$ of $\mathrm{Sr}$ in the Aleutian 778 lavas are derived from the mantle, as otherwise the mixing lines would become too curved to 779 encompass all the isotopic data.

780 It is currently unknown how mobile $\mathrm{Tl}$ is in fluids released from the subducting slab and, 781 therefore, it is difficult to quantify what the effect on $\mathrm{Tl}$ isotopes and abundances would be if 782 Aleutian lavas contained a significant fluid component from altered oceanic crust. We can obtain 783 qualitative information by examining the relation between the highly fluid mobile element Cs 784 (Kessel et al., 2005; Melzer and Wunder, 2000) and Tl across the Aleutian arc (Fig. 10). All bulk 785 endmembers in the Aleutian arc (e.g. mantle wedge, detrital and pelagic sediments, altered 786 oceanic crust and slab melts) display $\mathrm{Cs} / \mathrm{Tl}<10$, while lavas from the Central and Eastern 787 Aleutian Islands display $\mathrm{Cs} / \mathrm{Tl}=8-35$. Although $\mathrm{Cs}$ and $\mathrm{Tl}$ do not partition identically during 788 mantle melting (Nielsen et al., 2014), they are both so incompatible that mantle melts 
representing $>5 \%$ melting are not significantly fractionated from their mantle source. Thallium

790 concentration data from a range of arcs indicates that $\mathrm{Tl}$ is only mildly fluid mobile (Noll et al.,

791 1996) and, therefore, fluid dominated arc lavas should display high Cs/Tl. Thus, the high Cs/Tl

792 in Aleutian lavas are potentially caused by addition of a fluid with high Cs/Tl to the magma

793 source region. Alternatively, the high $\mathrm{Cs} / \mathrm{Tl}$ could be explained by a residual phase in the mantle

794 wedge or the slab that retains $\mathrm{Tl}$ over Cs. This residual phase could for example be sulfide or

795 phengite, both of which are expected to accommodate Tl (Kiseeva and Wood, 2013; Nielsen et

796 al., 2014; Prytulak et al., 2013). Phengite also incorporates Cs, but it has been shown that Cs is

797 the least compatible alkali metal in phengite (Hermann and Rubatto, 2009; Melzer and Wunder,

798 2000) due to its slightly larger ionic radius than the alkali metal cation site in phengite (Busigny

799 et al., 2003). The ionic radius of $\mathrm{Tl}$ is very similar to that of $\mathrm{Rb}$ (Shannon, 1976), which should

800 render $\mathrm{Tl}$ significantly more compatible in phengite than $\mathrm{Cs}$. Thus, high $\mathrm{Cs} / \mathrm{Tl}$ in arc lavas could

801 be due to phengite retention in the slab as well as residual sulfide in the mantle wedge. However,

802 future experimental work must be conducted in order to verify this inference.

803 Conversely, lavas from the Western Aleutians exhibit Cs/Tl that overlaps with MORB (Fig.

804 10) suggesting that the high $\mathrm{Cs} / \mathrm{Tl}$ component in the main Aleutian Islands is largely absent in

805 the Western Aleutians. Considering that sediment contributions are likely small in the Western

806 Aleutians (Kelemen et al., 2003; Yogodzinski et al., 2015; Yogodzinski et al., 1994), it follows

807 that the high $\mathrm{Cs} / \mathrm{Tl}$ ratios in the main Aleutian Islands probably originate from the sediment

808 component rather than fluids released from altered oceanic crust. This conclusion is supported by

809 the weak tendency for Eastern and Central Aleutian lavas with heavy $\mathrm{Tl}$ isotope compositions to

810 display the highest $\mathrm{Cs} / \mathrm{Tl}$ (Fig. 10). It should be noted that the process that generated high $\mathrm{Cs} / \mathrm{Tl}$

811 in the Aleutian lavas, be it fluid driven or mineralogical, would still need to occur after bulk 
812 mixing between the sediment and mantle components due to the mixing relations observed

813 between Tl-Sr-Nd-Pb isotopes (Figs. 7-9). However, given the lack of Tl partitioning data for

814 phengite and subduction fluids it is presently not possible to conclude if fluids are necessary to

815 account for the $\mathrm{Cs} / \mathrm{Tl}$ ratios observed in the Aleutian lavas.

\section{7. Conclusions}

818 We have conducted the first $\mathrm{Tl}$ isotope study of lavas covering the entire Aleutian arc and 819 subducting sediments located outboard of the main Aleutian Islands. Systematic changes are 820 observed in the average sediment $\mathrm{Tl}$ isotope composition from $\varepsilon^{205} \mathrm{Tl} \sim-2$, similar to the

821 continental crust and upper mantle, in the Eastern Aleutians to $\varepsilon^{205} \mathrm{Tl} \sim+4$ in the Central 822 Aleutians, which reflects a significant component of authigenic Mn oxides in these slowly 823 accumulating sediments. Lavas in the Aleutian Islands east of Kanaga generally mirror the trend 824 from $\varepsilon^{205} \mathrm{Tl} \sim-2$ in the Eastern Aleutians to $\varepsilon^{205} \mathrm{Tl} \sim+2$ in the Central Aleutians caused by the 825 changing subducted sediment composition across the arc. Simple models of sediment-mantle 826 mixing in $\mathrm{Nd}, \mathrm{Pb}, \mathrm{Sr}$ and $\mathrm{Tl}$ isotope space reveal that bulk sediment mixed with a depleted 827 mantle source can account for the isotopic variation observed in the Central and Eastern Aleutian 828 Islands. Our results are, therefore, consistent with recent models of sediment transport from the 829 slab to the mantle wedge whereby either pure sediment (Behn et al., 2011) or mélange diapirs 830 (Marschall and Schumacher, 2012) are the primary mode of adding sediments to the source 831 regions of arc lavas. However, bulk sediment mixing models require that processes occurring 832 after sediment-mantle mixing fractionate trace element ratios such as $\mathrm{Ce} / \mathrm{Pb}, \mathrm{Cs} / \mathrm{Tl}, \mathrm{Sr} / \mathrm{Nd}$, and $833 \mathrm{Th} / \mathrm{Nd}$. Both the sediment and mélange diapir models have not been explored in terms of the 834 resulting chemical signatures that can be generated in these scenarios. For example, it is not clear 
835 if sediment diapirs need to melt first in order to effectively mix with the mantle wedge in which

836 case trace element fractionation would likely occur prior to mixing and, therefore, not adequately

837 explain the isotope-isotope relationships (Fig. 9). The strong heterogeneity of mélange zones

838 sometimes observed in the field (Bebout, 2007) is perhaps not compatible with the relatively

839 homogenous isotopic signatures often observed for individual aleutian volcanoes (Kelemen et

840 al., 2003). Lastly, the high temperatures $\left(>1100^{\circ} \mathrm{C}\right)$ potentially experienced by sediment and

841 mélange diapirs in the mantle wedge could prevent significant trace element fractionation as

842 accessory phases might melt out and therefore not generate the required trace element

843 fractionation. Future experiments that reproduce the conditions experienced in sediment and

844 mélange diapirs will need to investigate the viability of these processes in generating the

845 observed major and trace element characteristics of arc lavas.

846 Alternative models that involve sediment melting in excess of 50\% may also be compatible

847 with the presented $\mathrm{Nd}, \mathrm{Pb}, \mathrm{Sr}$ and $\mathrm{Tl}$ isotopes. Such large degrees of melting could be driven by

848 an influx of AOC fluid with MORB-like isotope compositions (Skora and Blundy, 2010), which

849 may also deliver fractionated trace elements. Provided the sediment melt and AOC fluid had

850 similar trace element ratios, they have the potential to produce arrays that look like bulk mixing

851 but also generate trace element fractionations (e.g., high $\mathrm{Sr} / \mathrm{Nd}, \mathrm{Cs} / \mathrm{Tl}$ and $\mathrm{Pb} / \mathrm{Ce}$ ) observed in arc 852 lavas.

853 Thallium isotope systematics in Western Aleutian lavas show compositions slightly lighter

854 than the upper mantle, which implies a negligible sediment flux at this location and probably

855 involvement of low-temperature altered oceanic crust in the generation of these lavas. In general,

856 the lightest $\mathrm{Tl}$ isotope compositions are observed for the highest $\mathrm{Sr} / \mathrm{Y}$ ratios and most 
unradiogenic $\mathrm{Sr}$ and $\mathrm{Pb}$ isotope compositions, which may be consistent with derivation of these

858 lavas via melting of eclogitized altered oceanic crust.

\section{Acknowledgements}

This study used samples recovered during the Ocean Drilling Program. This study was funded by NSF grants EAR-1119373 and -1427310 to SGN and EAR-1456814 to TP. We thank Daniel Rasmussen and Louise Bolge for their chemistry lab and ICP-MS talents in analyzing data compilations, Peter Kelemen for discussions and Oliver Nebel and an anonymous reviewer for insightful comments that helped improve this manuscript.

\section{References}

Abouchami, W., Galer, S.J.G., Koschinsky, A., 1999. Pb and Nd isotopes in NE Atlantic Fe-Mn crusts: Proxies for trace metal paleosources and paleocean circulation. Geochim. Cosmochim. Acta. 63, 1489-1505.

Adam, J., Green, T., 2006. Trace element partitioning between mica- and amphibole-bearing garnet lherzolite and hydrous basanitic melt: 1 . Experimental results and the investigation of controls on partitioning behaviour. Contrib. Mineral. Petrol. 152, 1-17.

Baker, R.G.A., Rehkämper, M., Hinkley, T.K., Nielsen, S.G., Toutain, J.P., 2009. Investigation of thallium fluxes from subaerial volcanism-Implications for the present and past mass balance of thallium in the oceans. Geochim. Cosmochim. Acta. 73, 6340-6359.

Bebout, G.E., 1991. Field-Based Evidence for Devolatilization in Subduction Zones Implications for Arc Magmatism. Science 251, 413-416.

Bebout, G.E., 2007. Metamorphic chemical geodynamics of subduction zones. Earth Planet. Sci. Lett. 260, 373-393.

Behn, M.D., Kelemen, P.B., Hirth, G., Hacker, B.R., Massonne, H.J., 2011. Diapirs as the source of the sediment signature in arc lavas. Nature Geoscience 4, 641-646.

Ben Othmann, D., White, W.M., Patchett, J., 1989. The geochemistry of marine sediments, island arc magma genesis, and crust-mantle recycling. Earth Planet. Sci. Lett. 94, 1-21.

Busigny, V., Cartigny, P., Philippot, P., Ader, M., Javoy, M., 2003. Massive recycling of nitrogen and other fluid-mobile elements $(\mathrm{K}, \mathrm{Rb}, \mathrm{Cs}, \mathrm{H})$ in a cold slab environment: evidence from HP to UHP oceanic metasediments of the Schistes Lustres nappe (western Alps, Europe). Earth Planet. Sci. Lett. 215, 27-42. 
Byrne, R.H., 2002. Inorganic speciation of dissolved elements in seawater: the influence of $\mathrm{pH}$ on concentration ratios. Geochemical Transactions 3, 11-16.

Carpentier, M., Chauvel, C., Mattielli, N., 2008. Pb-Nd isotopic constraints on sedimentary input into the Lesser Antilles arc system. Earth Planet. Sci. Lett. 272, 199-211.

Carter, L.B., Skora, S., Blundy, J.D., De Hoog, J.C.M., Elliott, T., 2015. An Experimental Study of Trace Element Fluxes from Subducted Oceanic Crust. J. Petrol. 56, 1585-1605.

Class, C., Miller, D.M., Goldstein, S.L., Langmuir, C.H., 2000. Distinguishing melt and fluid subduction components in Umnak Volcanics, Aleutian Arc. Geochem. Geophys. Geosyst. 1, doi:10.1029/1999GC000010.

Coggon, R.M., Rehkämper, M., Atteck, C., Teagle, D.A.H., Alt, J.C., Cooper, M.J., 2014. Mineralogical and Microbial Controls on Thallium Uptake During Hydrothermal Alteration of the Upper Ocean Crust. Geochim. Cosmochim. Acta. 144, 25-42.

Defant, M.J., Drummond, M.S., 1990. Derivation of Some Modern Arc Magmas by Melting of Young Subducted Lithosphere. Nature 347, 662-665.

George, R., Turner, S., Hawkesworth, C., Morris, J., Nye, C., Ryan, J., Zheng, S.H., 2003. Melting processes and fluid and sediment transport rates along the Alaska-Aleutian arc from an integrated U-Th-Ra-Be isotope study. J. Geophys. Res.-Solid Earth 108.

Hegner, E., Tatsumoto, M., 1987. Pb, Sr, and Nd Isotopes in Basalts and Sulfides from the JuanDe-Fuca Ridge. J. Geophys. Res.-Solid Earth and Planets 92, 11380-11386.

Hein, J.R., Koschinsky, A., Bau, M., Manheim, F.T., Kang, J.-K., Roberts, L., 2000. Cobalt-rich ferromanganese crusts in the Pacific, in: Cronan, D.S. (Ed.), Handbook of Marine Mineral Deposits. CRC Press, Boca Raton, pp. 239-280.

Heinrichs, H., Schulz-Dobrick, B., Wedepohl, K.H., 1980. Terrestrial Geochemistry of Cd, Bi, $\mathrm{Tl}, \mathrm{Pb}, \mathrm{Zn}$ and $\mathrm{Rb}$. Geochim. Cosmochim. Acta. 44, 1519-1533.

Hermann, J., 2002. Allanite: thorium and light rare earth element carrier in subducted crust. Chem. Geol. 192, 289-306.

Hermann, J., Rubatto, D., 2009. Accessory phase control on the trace element signature of sediment melts in subduction zones. Chem. Geol. 265, 512-526.

Jackson, M.G., Hart, S.R., 2006. Strontium isotopes in melt inclusions from Samoan basalts: Implications for heterogeneity in the Samoan plume. Earth Planet. Sci. Lett. 245, 260277.

Jenner, F.E., O'Neill, H.S.C., 2012. Analysis of 60 elements in 616 ocean floor basaltic glasses. Geochem. Geophys. Geosyst. 13.

Jicha, B.R., Singer, B.S., Brophy, J.G., Fournelle, J.H., Johnson, C.M., Beard, B.L., Lapen, T.J., Mahlen, N.J., 2004. Variable impact of the subducted slab on Aleutian island arc magma sources: Evidence from $\mathrm{Sr}, \mathrm{Nd}, \mathrm{Pb}$, and $\mathrm{Hf}$ isotopes and trace element abundances. J. Petrol. 45, 1845-1875.

Jochum, K.P., Verma, S.P., 1996. Extreme enrichment of Sb, Tl and other trace elements in altered MORB. Chem. Geol. 130, 289-299.

Johnson, M.C., Plank, T., 1999. Dehydration and melting experiments constrain the fate of subducted sediments. Geochem. Geophys. Geosyst. 1.

Kay, R.W., 1978. Aleutian magnesian andesites - melts from subducted Pacific ocean crust. J. Volcanol. Geotherm. Res. 4, 117-132.

Kay, R.W., 1980. Volcanic Arc Magmas - Implications of a Melting-Mixing Model for Element Recycling in the Crust-Upper Mantle System. J Geol 88, 497-522. 
935

936

937

938

939

940

941

942

943

944

945

946

947

948

949

950

951

952

953

954

955

956

957

958

959

960

961

962

963

964

965

966

967

968

969

970

971

972

973

974

975

976

977

978

Kay, R.W., Kay, S.M., 1988. Crustal Recycling and the Aleutian Arc. Geochim. Cosmochim. Acta. 52, 1351-1359.

Kay, R.W., Sun, S.S., Lee-Hu, C.N., 1978. Pb and Sr isotopes in volcanic rocks from the Aleutian Islands and Pribilof Islands, Alaska. Geochim. Cosmochim. Acta. 42, 263-273.

Kay, S.M., Kay, R.W., 1994. Aleutian magmas in space and time, in: Plafker, G., Berg, H.C. (Eds.), The geology of Alaska. Geological Society of America, pp. 687-722.

Kelemen, P.B., Yogodzinski, G.M., Scholl, D.W., 2003. Along-strike Variation in Lavas of the Aleutian Island Arc: Implications for the Genesis of High Mg\# Andesite and the Continental Crust. Geophysical Monograph 138, 223-276.

Kessel, R., Schmidt, M.W., Ulmer, P., Pettke, T., 2005. Trace element signature of subductionzone fluids, melts and supercritical liquids at 120-180 km depth. Nature 437, 724-727.

King, R.L., Kohn, M.J., Eiler, J.M., 2003. Constraints on the petrologic structure of the subduction zone slab-mantle interface from Franciscan Complex exotic ultramafic blocks. Geological Society of America Bulletin 115, 1097-1109.

Kiseeva, E.S., Wood, B.J., 2013. A simple model for chalcophile element partitioning between sulphide and silicate liquids with geochemical applications. Earth Planet. Sci. Lett. 383, 68-81.

Ling, H.F., Burton, K.W., Onions, R.K., Kamber, B.S., vonBlanckenburg, F., Gibb, A.J., Hein, J.R., 1997. Evolution of $\mathrm{Nd}$ and $\mathrm{Pb}$ isotopes in Central Pacific seawater from ferromanganese crusts. Earth Planet. Sci. Lett. 146, 1-12.

Ling, H.F., Jiang, S.Y., Frank, M., Zhou, H.Y., Zhou, F., Lu, Z.L., Chen, X.M., Jiang, Y.H., Ge, C.D., 2005. Differing controls over the Cenozoic $\mathrm{Pb}$ and $\mathrm{Nd}$ isotope evolution of deepwater in the central North Pacific Ocean. Earth Planet. Sci. Lett. 232, 345-361.

Lugmair, G.W., Galer, S.J.G., 1992. Age and Isotopic Relationships among the Angrites Lewis Cliff-86010 and Angra-Dos-Reis. Geochim. Cosmochim. Acta. 56, 1673-1694.

Marschall, H.R., Schumacher, J.C., 2012. Arc magmas sourced from melange diapirs in subduction zones. Nature Geoscience 5, 862-867.

Melzer, S., Wunder, B., 2000. Island-arc basalt alkali ratios: Constraints from phengite-fluid partitioning experiments. Geology 28, 583-586.

Miller, D.M., Goldstein, S.L., Langmuir, C.H., 1994. CERIUM LEAD AND LEAD-ISOTOPE RATIOS IN ARC MAGMAS AND THE ENRICHMENT OF LEAD IN THE CONTINENTS. Nature 368, 514-520.

Morris, J.D., Leeman, W.P., Tera, F., 1990. The subducted component in island-arc lavas constraints from Be isotopes and B-Be systematics. Nature 344, 31-36.

Nielsen, S.G., Gannoun, A., Marnham, C., Burton, K.W., Halliday, A.N., Hein, J.R., 2011. New age for ferromanganese crust 109D-C and implications for isotopic records of lead, neodymium, hafnium, and thallium in the Pliocene Indian Ocean. Paleoceanography 26, PA2213, doi:2210.1029/2010PA002003.

Nielsen, S.G., Klein, F., Kading, T., Blusztajn, J., Wickham, K., 2015. Thallium as a Tracer of Fluid-Rock Interaction in the Shallow Mariana Forearc. Earth Planet. Sci. Lett. 430, 416426.

Nielsen, S.G., Mar-Gerrison, S., Gannoun, A., LaRowe, D., Klemm, V., Halliday, A.N., Burton, K.W., Hein, J.R., 2009. Thallium isotope evidence for a permanent increase in marine organic carbon export in the early Eocene. Earth Planet. Sci. Lett. 278, 297-307. 
Nielsen, S.G., Rehkämper, M., 2011. Thallium isotopes and their application to problems in earth and environmental science, in: Baskaran, M. (Ed.), Handbook of Environmental Isotope Geochemistry. Springer, pp. 247-270.

Nielsen, S.G., Rehkämper, M., Baker, J., Halliday, A.N., 2004. The precise and accurate determination of thallium isotope compositions and concentrations for water samples by MC-ICPMS. Chem. Geol. 204, 109-124.

Nielsen, S.G., Rehkämper, M., Brandon, A.D., Norman, M.D., Turner, S., O'Reilly, S.Y., 2007. Thallium isotopes in Iceland and Azores lavas - Implications for the role of altered crust and mantle geochemistry. Earth Planet. Sci. Lett. 264, 332-345.

Nielsen, S.G., Rehkämper, M., Halliday, A.N., 2006a. Large thallium isotopic variations in iron meteorites and evidence for lead-205 in the early solar system. Geochim. Cosmochim. Acta. 70, 2643-2657.

Nielsen, S.G., Rehkämper, M., Norman, M.D., Halliday, A.N., Harrison, D., 2006b. Thallium isotopic evidence for ferromanganese sediments in the mantle source of Hawaiian basalts. Nature 439, 314-317.

Nielsen, S.G., Rehkämper, M., Porcelli, D., Andersson, P., Halliday, A.N., Swarzenski, P.W., Latkoczy, C., Gunther, D., 2005. Thallium isotope composition of the upper continental crust and rivers - An investigation of the continental sources of dissolved marine thallium. Geochim. Cosmochim. Acta. 69, 2007-2019.

Nielsen, S.G., Rehkämper, M., Teagle, D.A.H., Alt, J.C., Butterfield, D., Halliday, A.N., 2006c. Hydrothermal fluid fluxes calculated from the isotopic mass balance of thallium in the ocean crust. Earth Planet. Sci. Lett. 251, 120-133.

Nielsen, S.G., Shimizu, N., Lee, C.T.A., Behn, M., 2014. Chalcophile behavior of thallium during MORB melting and implications for the sulfur content of the mantle. Geochem. Geophys. Geosyst. 15, 4905-4919.

Nielsen, S.G., Wasylenki, L.E., Rehkämper, M., Peacock, C.L., Xue, Z., Moon, E.M., 2013. Towards an understanding of thallium isotope fractionation during adsorption to manganese oxides. Geochim. Cosmochim. Acta. 117, 252-265.

Noll, P.D., Newsom, H.E., Leeman, W.P., Ryan, J.G., 1996. The role of hydrothermal fluids in the production of subduction zone magmas: Evidence from siderophile and chalcophile trace elements and boron. Geochim. Cosmochim. Acta. 60, 587-611.

Peacock, C.L., Moon, E.M., 2012. Oxidative scavenging of thallium by birnessite: Controls on thallium sorption and stable isotope fractionation in marine ferromanganese precipitates. Geochim. Cosmochim. Acta. 84, 297-313.

Plank, T., 2005. Constraints from thorium/lanthanum on sediment recycling at subduction zones and the evolution of the continents. J. Petrol. 46, 921-944.

Plank, T., Langmuir, C.H., 1998. The chemical composition of subducting sediment and its consequences for the crust and mantle. Chem. Geol. 145, 325-394.

Prytulak, J., Nielsen, S.G., Plank, T., Barker, M., Elliott, T., 2013. Assessing the utility of thallium and thallium isotopes for tracing subduction zone inputs to the Mariana arc. Chem. Geol. 345, 139-149.

Rabinowitz, H.S., Savage, H.M., Plank, T., Polissar, P.J., Kirkpatrick, J.D., Rowe, C.D., 2015. Multiple major faults at the Japan Trench: Chemostratigraphy of the plate boundary at IODP Exp. 343: JFAST. Earth Planet. Sci. Lett. 423, 57-66.

Rea, D.K., Basov, I.A., Janecek, T.R., Palmer-Julson, A., 1993. Sites 885/886. Proceedings of the Ocean Drilling Program, Initial Reports 145, 303-334. 
1025

1026

1027

1028

1029

1030

1031

1032

1033

1034

1035

1036

1037

1038

1039

1040

1041

1042

1043

1044

1045

1046

1047

1048

1049

1050

1051

1052

1053

1054

1055

1056

1057

1058

1059

1060

1061

1062

1063

1064

1065

1066

1067

1068

1069

1070

Rehkämper, M., Frank, M., Hein, J.R., Halliday, A., 2004. Cenozoic marine geochemistry of thallium deduced from isotopic studies of ferromanganese crusts and pelagic sediments. Earth Planet. Sci. Lett. 219, 77-91.

Rehkämper, M., Frank, M., Hein, J.R., Porcelli, D., Halliday, A., Ingri, J., Liebetrau, V., 2002. Thallium isotope variations in seawater and hydrogenetic, diagenetic, and hydrothermal ferromanganese deposits. Earth Planet. Sci. Lett. 197, 65-81.

Rehkämper, M., Halliday, A.N., 1999. The precise measurement of Tl isotopic compositions by MC- ICPMS: Application to the analysis of geological materials and meteorites. Geochim. Cosmochim. Acta. 63, 935-944.

Ryan, J.G., Chauvel, C., 2014. 3.13 - The Subduction-Zone Filter and the Impact of Recycled Materials on the Evolution of the Mantle, in: Turekian, H.D.H.K. (Ed.), Treatise on Geochemistry (Second Edition). Elsevier, Oxford, pp. 479-508.

Schauble, E.A., 2007. Role of nuclear volume in driving equilibrium stable isotope fractionation of mercury, thallium, and other very heavy elements. Geochim. Cosmochim. Acta. 71, 2170-2189.

Scher, H.D., Delaney, M.L., 2010. Breaking the glass ceiling for high resolution Nd isotope records in early Cenozoic paleoceanography. Chem. Geol. 269, 329-338.

Schiano, P., Dupré, B., Lewin, E., 1993. Application of element concentration variability to the study of basalt alteration (Fangataufa atoll, French Polynesia). Chem. Geol. 104, 99-124.

Shannon, R.D., 1976. Revised effective ionic radii and systematic studies of interatomic distances in halides and chalcogenides. Acta Crystallographica A32, 751-767.

Shaw, D.M., 1952. The geochemistry of thallium. Geochim. Cosmochim. Acta. 2, 118-154.

Singer, B.S., Jicha, B.R., Leeman, W.P., Rogers, N.W., Thirlwall, M.F., Ryan, J., Nicolaysen, K.E., 2007. Along-strike trace element and isotopic variation in Aleutian Island arc basalt: Subduction melts sediments and dehydrates serpentine. J. Geophys. Res.-Solid Earth 112.

Skora, S., Blundy, J., 2010. High-pressure Hydrous Phase Relations of Radiolarian Clay and Implications for the Involvement of Subducted Sediment in Arc Magmatism. J. Petrol. 51, 2211-2243.

Snoeckx, H., Rea, D.K., Jones, C.E., Lynn Ingram, B., 1995. EOLIAN AND SILICA DEPOSITION IN THE CENTRAL NORTH PACIFIC: RESULTS FROM SITES 885/886. Proceedings Of the Ocean Drilling Program, Scientific Results 145, 219-230.

Staudigel, H., Davies, G.R., Hart, S.R., Marchant, K.M., Smith, B.M., 1995. Large scale isotopic $\mathrm{Sr}, \mathrm{Nd}$ and $\mathrm{O}$ isotopic anatomy of altered oceanic crust: DSDP/ODP sites 417/418. Earth Planet. Sci. Lett. 130, 169-185.

Sun, S.S., 1980. Lead Isotopic Study of Young Volcanic-Rocks from Mid-Ocean Ridges, Ocean Islands and Island Arcs. Philosophical Transactions of the Royal Society a-Mathematical Physical and Engineering Sciences 297, 409-445.

Tanaka, T., Togashi, S., Kamioka, H., Amakawa, H., Kagami, H., Hamamoto, T., Yuhara, M., Orihashi, Y., Yoneda, S., Shimizu, H., Kunimaru, T., Takahashi, K., Yanagi, T., Nakano, T., Fujimaki, H., Shinjo, R., Asahara, Y., Tanimizu, M., Dragusanu, C., 2000. JNdi-1: a neodymium isotopic reference in consistency with LaJolla neodymium. Chem. Geol. 168, 279-281.

Teagle, D.A.H., Bickle, M.J., Alt, J.C., 2003. Recharge flux to ocean-ridge black smoker systems: a geochemical estimate from ODP Hole 504B. Earth Planet. Sci. Lett. 210, 81 89. 
1071

1072

1073

1074

1075

1076

1077

1078

1079

1080

1081

1082

1083

1084

1085

1086

1087

1088

1089

1090

1091

1092

1093

1094

1095

1096

1097

1098

1099

1100

1101

1102

1103

1104

1105

1106

1107

1108

1109

1110

1111

1112

1113

1114

1115

1116

Tera, F., Brown, L., Morris, J., Sacks, I.S., Klein, J., Middleton, R., 1986. SEDIMENT INCORPORATION IN ISLAND-ARC MAGMAS - INFERENCES FROM BE-10. Geochim. Cosmochim. Acta. 50, 535-550.

Thirlwall, M.F., Graham, A.M., Arculus, R.J., Harmon, R.S., Macpherson, C.G., 1996. Resolution of the effects of crustal assimilation, sediment subduction, and fluid transport in island arc magmas: $\mathrm{Pb}-\mathrm{Sr}-\mathrm{Nd}-\mathrm{O}$ isotope geochemistry of Grenada, Lesser Antilles. Geochim. Cosmochim. Acta. 60, 4785-4810.

Todt, W., Cliff, R.A., Hanser, A., Hofmann, A.W., 1996. Evaluation of a 202Pb-205Pb double spike for high-precision lead isotope analysis. American Geophysical Union Monograph 95, 429-437.

Vervoort, J.D., Plank, T., Prytulak, J., 2011. The Hf-Nd isotopic composition of marine sediments. Geochim. Cosmochim. Acta. 75, 5903-5926.

Von Drach, V., Marsh, B.D., Wasserburg, G.J., 1986. Nd and Sr Isotopes in the Aleutians Multicomponent Parenthood of Island-Arc Magmas. Contrib. Mineral. Petrol. 92, 13-34.

Von Huene, R., Scholl, D.W., 1991. Observations at Convergent Margins Concerning Sediment Subduction, Subduction Erosion, and the Growth of Continental-Crust. Rev. Geophys. 29, 279-316.

Wedepohl, K.H., 1995. The composition of the continental crust. Geochim. Cosmochim. Acta. 59, 1217-1232.

Weis, D., Kieffer, B., Maerschalk, C., Barling, J., de Jong, J., Williams, G.A., Hanano, D., Pretorius, W., Mattielli, N., Scoates, J.S., Goolaerts, A., Friedman, R.M., Mahoney, J.B., 2006. High-precision isotopic characterization of USGS reference materials by TIMS and MC-ICP-MS. Geochem. Geophys. Geosyst. 7.

Weis, D., Kieffer, B., Maerschalk, C., Pretorius, W., Barling, J., 2005. High-precision Pb-Sr-NdHf isotopic characterization of USGS BHVO-1 and BHVO-2 reference materials. Geochem. Geophys. Geosyst. 6.

White, W.M., Dupré, B., 1986. Sediment subduction and magma genesis in the Lesser Antilles: Isotopic and trace element constraints. Journal of Geophysical Research 91, 5927-5941.

Workman, R.K., Hart, S.R., 2005. Major and trace element composition of the depleted MORB mantle (DMM). Earth Planet. Sci. Lett. 231, 53-72.

Yogodzinski, G.M., Brown, S.T., Kelemen, P.B., Vervoort, J.D., Portnyagin, M., Sims, K.W.W., Hoernle, K., Jicha, B.R., Werner, R., 2015. The Role of Subducted Basalt in the Source of Island Arc Magmas: Evidence from Seafloor Lavas of the Western Aleutians. J. Petrol. $56,441-492$.

Yogodzinski, G.M., Kay, R.W., Volynets, O.N., Koloskov, A.V., Kay, S.M., 1995. Magnesian Andesite in the Western Aleutian Komandorsky Region - Implications for Slab Melting and Processes in the Mantle Wedge. Geological Society of America Bulletin 107, 505519.

Yogodzinski, G.M., Lees, J.M., Churikova, T.G., Dorendorf, F., Woerner, G., Volynets, O.N., 2001. Geochemical evidence for the melting of subducting oceanic lithosphere at plate edges. Nature 409, 500-504.

Yogodzinski, G.M., Vervoort, J.D., Brown, S.T., Gerseny, M., 2011. Subduction controls of Hf and Nd isotopes in lavas of the Aleutian island arc. Earth Planet. Sci. Lett. 300, 226-238. 
1117 Yogodzinski, G.M., Volynets, O.N., Koloskov, A.V., Seliverstov, N.I., Matvenkov, V.V., 1994. 1118 Magnesian Andesites and the Subduction Component in a Strongly Calc-Alkaline Series at Piip Volcano, Far Western Aleutians. J. Petrol. 35, 163-204. 
1122 Figure 1: Map of the Aleutian arc. Arrows indicate the locations of the lavas analyzed in this 1123 study. The colors used for the different lava locations are repeated throughout all the subsequent 1124 figures in this paper where lavas from multiple locations are plotted. Also shown are the three 1125 sediment drill cores investigated in order to characterize the sediment input flux to the arc.

1127 Figure 2: Thallium isotope composition and concentration for individual sediment samples 1128 from DSDP 178 (dark green), DSDP 183 (light green) and ODP 886C (blue). These colors 1129 mimic those used for the lavas whereby the eastern-most sediment core is dark green followed 1130 by light green and blue. The large symbols indicate the concentration weighted average $\mathrm{Tl}$ 1131 isotope compositions and concentrations for each of the three sediment cores. Although DSDP 1132183 and ODP 886C both contain pelagic components with heavy $\mathrm{Tl}$ isotopes and detrital 1133 components with $\varepsilon^{205} \mathrm{Tl} \sim-2$, ODP 886C clearly is much more dominated by the pelagic 1134 components than DSDP 183.

1136 Figure 3: Ce/Tl ratios plotted against $\mathrm{Tl}$ isotope composition for all Aleutian lavas 1137 investigated in this study. Also shown is the depleted mid ocean ridge basalt mantle (DMM) as 1138 well as the average compositions for detrital (DSDP 178 and 183) and pelagic (ODP 886C) 1139 sediments. Note that the legend colors follow that of the map in figure 1 and is the same for all 1140 subsequent figures with lavas from multiple locations. 
Figure 4: $\mathrm{Ce} / \mathrm{Tl}$ plotted against $\mathrm{Th} / \mathrm{Rb}$ for all subaerial lavas analyzed in this study. Subaerial

1143 aqueous alteration of basaltic lavas preferentially removes alkali metals and given the similarity

1144 of the ionic charge and radius between $\mathrm{Tl}$ and the alkali metals similar loss of $\mathrm{Tl}$ is likely during

1145 subaerial alteration. Hence, samples with high $\mathrm{Ce} / \mathrm{Tl}$ and $\mathrm{Th} / \mathrm{Rb}$ are probably affected by post

1146 eruption alteration (see text for further details).

1148 Figure 5: Potassium plotted against $\mathrm{Tl}$ concentrations in lavas from Korovin volcano.

1149 Samples broadly follow a fractional crystallization trend. The two arrows indicate the evolution

1150 of primitive magmas from fractional crystallization assuming partition coefficients for $\mathrm{K}$ and $\mathrm{Tl}$

1151 of 0 .

1152

1153 Figure 6: Charts showing the $\mathrm{Tl}$ isotopic composition of sediments from the three drill holes

1154 investigated as a function of depth. It is evident that sediment cores located further west, and

1155 thereby more distally to the continent, contain more sections with $\mathrm{Tl}$ isotope compositions that

1156 are heavier than the continental crust. Grey bars denote the $\mathrm{Tl}$ isotope composition of the

1157 continental crust and upper mantle (Nielsen et al., 2006b; Nielsen et al., 2005).

$1159 \quad$ Figure 7: Thallium isotopes plotted against $\mathrm{Pb}$ isotope ratios. Only samples that are not 1160 affected by subaerial weathering, assimilation, contamination or degassing are shown (see text 1161 for details). Symbol colors as in figure 3. Also shown are mixing lines between depleted mantle 1162 and bulk detrital (DSDP 178 and 183) and pelagic (ODP 886C) sediments. Dashed lines of 1163 constant sediment addition are indicated at $0.2 \%$ by weight intervals. The $\mathrm{Pb}$ isotope 1164 composition of the depleted mantle was taken from the most proximal MORB sample, which is 
1165 from the northern Juan de Fuca ridge (Hegner and Tatsumoto, 1987). A Pb concentration of 28

$1166 \mathrm{ng} / \mathrm{g}$ for the DMM is used, which is based on $\mathrm{Ce} / \mathrm{Tl} l_{\mathrm{DMM}}=1110$ and $\mathrm{Pb} / \mathrm{Tl} \mathrm{DMM}_{\mathrm{DM}}=56$ (Nielsen et

1167 al., 2014) and a Ce concentration of $0.55 \mu \mathrm{g} / \mathrm{g}$ (Workman and Hart, 2005). The Tl isotope 1168 composition of the upper mantle is $\varepsilon^{205} \mathrm{Tl}=-2$ (Nielsen et al., 2006b). The Pb isotope

1169 compositions and concentrations for detrital (DSDP 178 and 183) sediments were taken from

1170 (Plank and Langmuir, 1998), whereas $\mathrm{Pb}$ data for pelagic (ODP 886C) sediment as well as all

1171 sedimentary Tl data was taken from Table 5 in this study.

1172

1173 Figure 8: Thallium isotopes plotted against (a) $\mathrm{Sr}$ and (b) $\mathrm{Nd}$ isotope ratios. Only samples

1174 that are not affected by subaerial weathering, assimilation, contamination or degassing are shown

1175 (see text for details). Symbol colors as in figure 3. Grey areas denote the Western Aleutian

1176 samples except one (for $\mathrm{Sr}$ isotopes) or three (for $\mathrm{Nd}$ isotopes) outliers. Also shown are mixing

1177 lines between depleted mantle and bulk detrital (DSDP 178 and 183) and pelagic (ODP 886C)

1178 sediments. Dashed lines of constant sediment addition are indicated at $0.2 \%$ by weight intervals.

1179 The $\mathrm{Nd}$ and $\mathrm{Sr}$ isotope composition of the depleted mantle was taken from the most proximal

1180 MORB sample, which is from the northern Juan de Fuca ridge (Hegner and Tatsumoto, 1987).

1181 Concentrations in the DMM of $\mathrm{Sr}=7.66 \mu \mathrm{g} / \mathrm{g}$ and $\mathrm{Nd}=0.58 \mu \mathrm{g} / \mathrm{g}$ were used, which were taken

1182 from Workman and Hart (2005). The $\mathrm{Tl}$ isotope composition of the upper mantle is $\varepsilon^{205} \mathrm{Tl}=-2$

1183 and the $\mathrm{Tl}$ content of the $\mathrm{DMM}$ was inferred from $\mathrm{Pb} / \mathrm{Tl} \sim 56$ (Nielsen et al., 2014). The $\mathrm{Nd}$ and

$1184 \mathrm{Sr}$ isotope compositions and concentrations for detrital (DSDP 178 and 183) sediments were

1185 taken from (Plank and Langmuir, 1998; Vervoort et al., 2011), whereas Nd and Sr data for

1186 pelagic (ODP 886C) sediment as well as all sedimentary Tl data was taken from Table 5 in this

1187 study. 
Figure 9: Nd and Sr isotope compositions plotted against each other. Symbol colors as in

1190 figure 3, except the Western Aleutian samples that are denoted by grey area. Additional data

1191 from previous studies of the Aleutian Islands east of Kanaga are plotted for comparison (Class et

1192 al., 2000; George et al., 2003; Jicha et al., 2004; Singer et al., 2007; Yogodzinski et al., 2011).

1193 Also shown are mixing lines (bold lines) between depleted mantle and bulk detrital (DSDP 178

1194 and 183) and pelagic (ODP 886C) sediments. Thin dashed lines of constant sediment addition

1195 are indicated at $0.2 \%$ by weight intervals. The $\mathrm{Nd}$ and $\mathrm{Sr}$ isotope composition of the depleted

1196 mantle was taken from the most proximal MORB sample, which is from the northern Juan de

1197 Fuca ridge (Hegner and Tatsumoto, 1987). Concentrations in the DMM of Sr $=7.66 \mu \mathrm{g} / \mathrm{g}$ and $\mathrm{Nd}$

$1198=0.58 \mu \mathrm{g} / \mathrm{g}$ were used, which were taken from Workman and Hart (2005).

1199 A second set of bold dashed mixing lines between DMM and sediment melts are also 1200 shown. These mixing lines were constructed by generating $20 \%$ melts from the detrital and 1201 pelagic sediment endmembers and using melt-residue partition coefficients of $\mathrm{D}_{\mathrm{Sr}}=7.3$ and $\mathrm{D}_{\mathrm{Nd}}$

$1202=0.35$, which represents the average values recorded in sediment melting experiments by 1203 Hermann and Rubatto (2009) with temperatures from $750-900^{\circ} \mathrm{C}$.

1205 Figure 10: Thallium isotope compositions plotted against Cs/Tl ratio for Aleutian lavas from 1206 this study. Only samples that are not affected by subaerial weathering, assimilation, 1207 contamination or degassing are shown (see text for details). Symbol colors as in figure 3. Also 1208 shown are the values for detrital (DSDP 178 and 183) and pelagic (ODP 886C) sediments as well 1209 as an estimated value for altered oceanic crust (AOC) (Nielsen et al., 2006c) and the DMM 1210 (Nielsen et al., 2006b; Nielsen et al., 2014). It is notable that many of the Central and Eastern 
1211 Aleutian lavas display $\mathrm{Cs} / \mathrm{Tl}$ higher than any of the bulk components contributing to the lavas.

1212 This effect could either be explained by the involvement of Cs-rich fluids or preferential 1213 retention of $\mathrm{Tl}$ in phengite (see text for details).

1214 
1215 Table 1: Samples selected from ODP 886C

\begin{tabular}{|c|c|c|c|c|c|}
\hline ODP sample ID & $\begin{array}{l}\text { Depth } \\
\text { (mbsf) }\end{array}$ & Lithology & Unit & $\begin{array}{c}\text { Unit density } \\
\left(\mathrm{g} / \mathrm{cm}^{3}\right)\end{array}$ & $\begin{array}{c}\text { Unit } \\
\text { thickness (m) }\end{array}$ \\
\hline $1 \mathrm{H} 360-62 \mathrm{~cm}$ & 3.61 & Reddish brown clay & 1 & & \\
\hline $1 \mathrm{H} 470-72 \mathrm{~cm}$ & 5.21 & Reddish brown clay & 1 & 1.5 & 6.8 \\
\hline $2 \mathrm{H} 155-57 \mathrm{~cm}$ & 7.36 & Dark brown spicule clay & 2 & & \\
\hline $2 \mathrm{H} 465-67 \mathrm{~cm}$ & 11.96 & Light brown spicule clay & 2 & & \\
\hline $3 \mathrm{H} 190-92 \mathrm{~cm}$ & 17.21 & Brown diatom clay & 2 & 1.45 & 15.4 \\
\hline $3 \mathrm{H} 5$ 60-62cm & 22.91 & Light brown diatom ooze & 3 & & \\
\hline $4 \mathrm{H} 180-82 \mathrm{~cm}$ & 26.61 & Light brown diatom ooze & 3 & & \\
\hline $4 \mathrm{H} 530-32 \mathrm{~cm}$ & 30.61 & Light brown diatom ooze & 3 & & \\
\hline $5 \mathrm{H} 150-52 \mathrm{~cm}$ & 35.81 & Light brown diatom ooze & 3 & & \\
\hline $5 \mathrm{H} 345-47 \mathrm{~cm}$ & 38.76 & Light brown diatom ooze & 3 & & \\
\hline $6 \mathrm{H} 270-72 \mathrm{~cm}$ & 47.01 & Light brown diatom ooze & 3 & 1.4 & 26.5 \\
\hline $6 \mathrm{H} 3120-122 \mathrm{~cm}$ & 49.01 & Mn nodule & 4 & 4 & 0.2 \\
\hline 7H $358-60 \mathrm{~cm}$ & 57.89 & Dark brown clay & 5 & & \\
\hline $7 \mathrm{H} 573-75 \mathrm{~cm}$ & 61.04 & Dark brown clay & 5 & 1.5 & 15 \\
\hline $8 \mathrm{H} 148-50 \mathrm{~cm}$ & 64.29 & Dark brown clay & 6 & & \\
\hline $8 \mathrm{H} 458-60 \mathrm{~cm}$ & 68.89 & Dark brown clay & 6 & 1.55 & 8.5 \\
\hline
\end{tabular}


Table 2: Tl, $\mathrm{Sr}, \mathrm{Nd}$ and $\mathrm{Pb}$ isotopes for Main Arc lavas

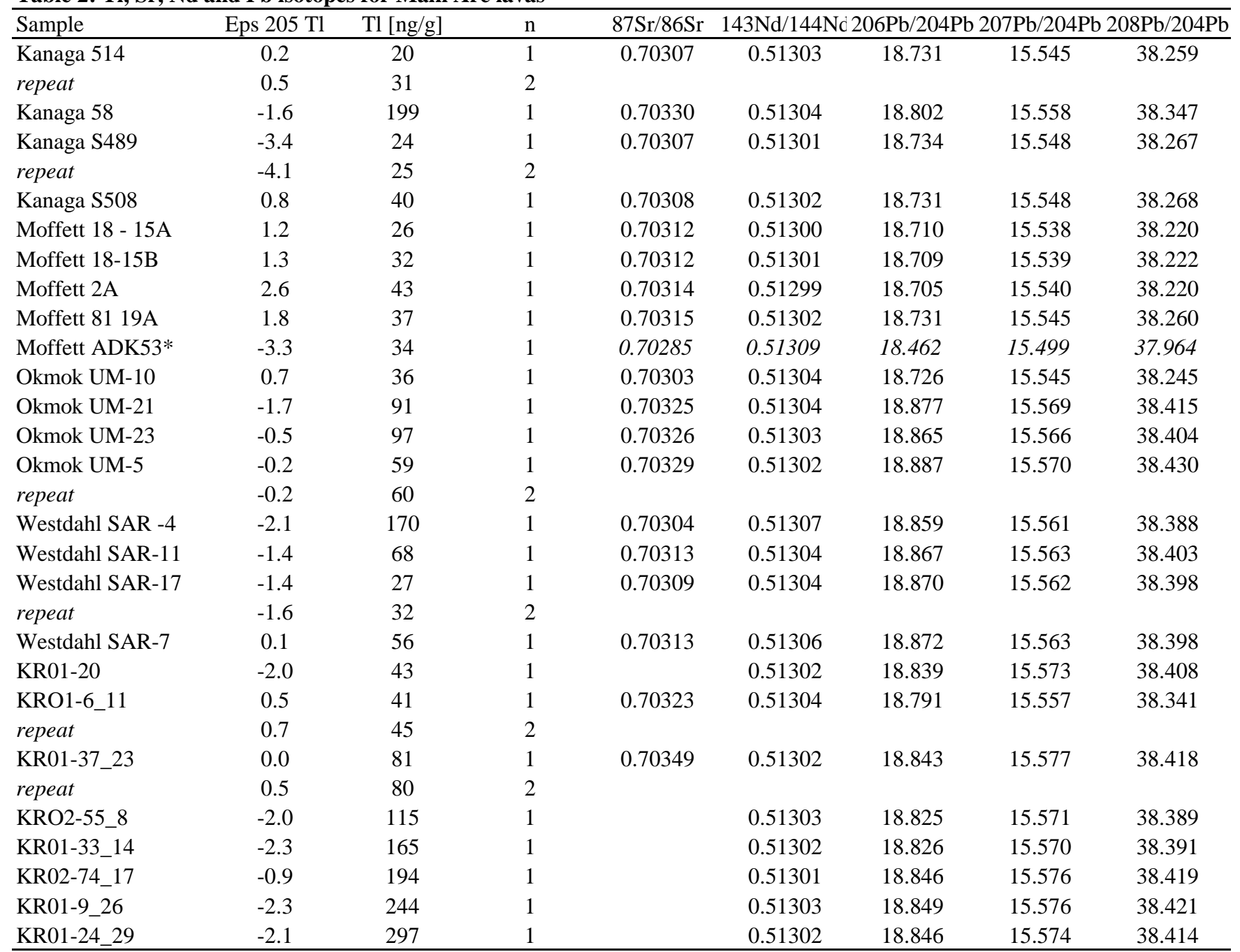

* - Radiogenic isotope data from (Kay, 1978; Sun, 1973) 
Table 3: TI concentrations and isotopic compositions of Western Aleutian lavas

\begin{tabular}{|c|c|c|c|c|c|c|c|c|c|c|c|c|c|c|c|c|c|c|c|c|}
\hline Sample & $\begin{array}{c}\mathrm{tn} 182 \_01 \_0 \\
01\end{array}$ & $\begin{array}{c}\text { tn182_01_0 } \\
07 \\
\end{array}$ & $\begin{array}{c}\text { tn182_03_0 } \\
02\end{array}$ & $\begin{array}{c}\text { tn182_04_0 } \\
03\end{array}$ & $\begin{array}{c}\mathrm{tn} 182 \_05 \_0 \\
01\end{array}$ & $\begin{array}{c}\mathrm{tn} 182 \_07 \_0 \\
02\end{array}$ & $\begin{array}{c}\text { tn182_07_0 } \\
05\end{array}$ & $\begin{array}{c}\text { tn182_07_0 } \\
09 \\
\end{array}$ & $\begin{array}{c}\text { tn182_08_0 } \\
03\end{array}$ & $\begin{array}{c}\text { tn182_08_0 } \\
13\end{array}$ & $\begin{array}{c}\text { tn182_08_0 } \\
14\end{array}$ & $\begin{array}{c}\text { tn182_09_0 } \\
01\end{array}$ & $\begin{array}{c}\operatorname{tn} 182 \_10 \_0 \\
03\end{array}$ & $\begin{array}{c}\operatorname{tn} 182 \_10 \_0 \\
04\end{array}$ & $\begin{array}{c}\text { tn182_11_0 } \\
01\end{array}$ & $\begin{array}{c}\text { tn182_11_0 } \\
04\end{array}$ & $\begin{array}{c}\text { tn182_13_0 } \\
01\end{array}$ & $\begin{array}{c}\text { SO201-1b- } \\
33-001 \\
\end{array}$ & $\begin{array}{c}\text { SO201-1b- } \\
35-004 \\
\end{array}$ & $\begin{array}{c}\text { SO201-1b- } \\
36-003\end{array}$ \\
\hline \multicolumn{21}{|c|}{ 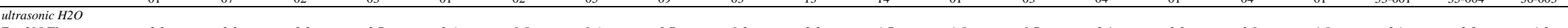 } \\
\hline Eps $205 \mathrm{Tl}$ & -3.2 & -2.2 & -2.2 & -2.7 & -2.6 & -0.5 & 0.6 & -2.7 & -9.3 & -2.3 & -1.7 & -1.5 & -0.7 & -3.4 & -2.2 & -2.0 & -1.8 & -3.1 & -2.3 & -1.3 \\
\hline $\mathrm{Tl}[\mathrm{ng} / \mathrm{g}]$ & 110 & 59 & 54 & 65 & 54 & 69 & 23 & 151 & 476 & 69 & 66 & 83 & 124 & 298 & 123 & 79 & 94 & 56 & 48 & 33 \\
\hline \multicolumn{21}{|l|}{ Ultrasonic $\mathrm{IM} \mathrm{HCl}$} \\
\hline Eps $205 \mathrm{Tl}$ & & & & & & -1.8 & 0.9 & & -9.2 & & & & 0.6 & & & & & & & \\
\hline $\mathrm{Tl}[\mathrm{ng} / \mathrm{g}]$ & & & & & & 107 & 30 & & 465 & & & & 113 & & & & & & & \\
\hline \multicolumn{21}{|l|}{ Ultrasonic $6 \mathrm{M} \mathrm{HCl}$} \\
\hline Eps $205 \mathrm{Tl}$ & & & & & & -1.8 & 0.7 & -2.5 & & & & & -1.0 & & & & & & & \\
\hline $\mathrm{Tl}[\mathrm{ng} / \mathrm{g}]$ & & & & & & 106 & 30 & 184 & & & & & 160 & & & & & & & \\
\hline \multicolumn{21}{|l|}{ No treatment } \\
\hline Eps $205 \mathrm{Tl}$ & & & & & & 0.3 & 2.2 & & -9.5 & & & & -0.6 & & & & & & & \\
\hline $\mathrm{Tl}[\mathrm{ng} / \mathrm{g}]$ & & & & & & 17 & 23 & & 877 & & & & 162 & & & & & & & \\
\hline \multicolumn{21}{|l|}{ IM HCl leach } \\
\hline Eps $205 \mathrm{Tl}$ & & & & & & 9.8 & & & 0.3 & & & & & & & & & & & \\
\hline $\mathrm{Tl}[\mathrm{ng} / \mathrm{g}]$ & & & & & & 2 & & & 9 & & & & & & & & & & & \\
\hline
\end{tabular}

Preferred Values

(1)

$\underline{\text { Tl }[\mathrm{ng} / \mathrm{g}]}$

$\begin{array}{ccccccccccc}-3.2 & -2.2 & -2.2 & -2.7 & -2.6 & -1.8 & 0.7 & -2.6 & -9.3 & -2.3 & -1.7 \\ 110 & 59 & 54 & 65 & 54 & 107 & 27 & 168 & 470 & 69 & 66\end{array}$

$-1.5 \quad-0.4$

\begin{tabular}{lllllll}
-3.4 & -2.2 & -2.0 & -1.8 & -3.1 & -2.3 & -1.3 \\
298 & 123 & 79 & 94 & 56 & 48 & 33 \\
\hline
\end{tabular}




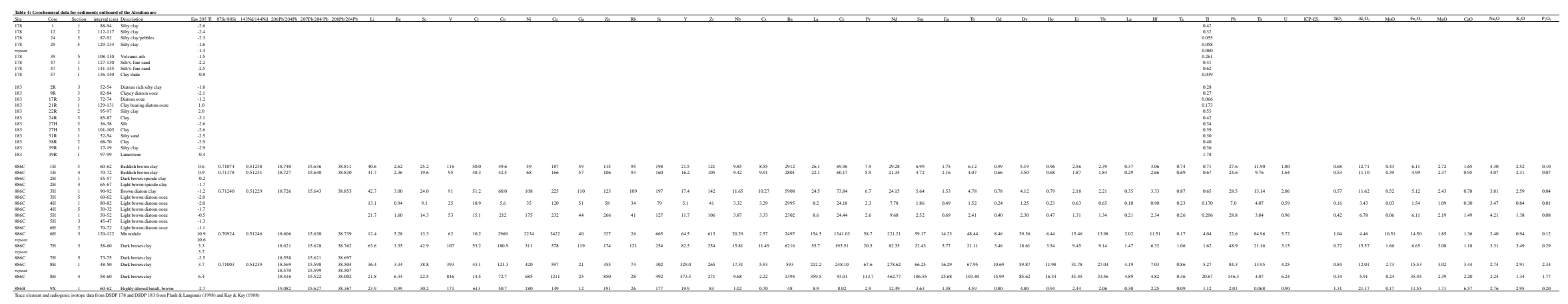


1218 Table 5: Weighted average subducted sediment components

\begin{tabular}{|c|c|c|}
\hline Parameter & East Aleutian Sediment ${ }^{\#}$ & Cent. Aleutian Sediment \\
\hline $\mathrm{Rb}$ & 57 & 77.1 \\
\hline Cs & 3.4 & 7.1 \\
\hline $\mathrm{Sr}$ & 245 & 203 \\
\hline $\mathrm{Ba}$ & 2074 & 3910 \\
\hline $\mathrm{La}$ & 18.0 & 58.8 \\
\hline $\mathrm{Ce}$ & 39.0 & 103 \\
\hline $\mathrm{Nd}$ & 19.1 & 75.7 \\
\hline $\mathrm{Tl}$ & 0.31 & 2.25 \\
\hline $\mathrm{Pb}$ & 12.9 & 39.6 \\
\hline Th & 5.5 & 11.4 \\
\hline $\mathrm{U}$ & 2.4 & 2.23 \\
\hline${ }^{87} \mathrm{Sr} /{ }^{88} \mathrm{Sr}$ & 0.7064 & 0.711 \\
\hline${ }^{143} \mathrm{Nd} /{ }^{144} \mathrm{Nd}$ & 0.51261 & 0.5124 \\
\hline${ }^{206} \mathrm{~Pb} /{ }^{204} \mathrm{~Pb}$ & 19.04 & 18.61 \\
\hline${ }^{207} \mathrm{~Pb} /{ }^{204} \mathrm{~Pb}$ & 15.63 & 15.61 \\
\hline${ }^{208} \mathrm{~Pb} /{ }^{204} \mathrm{~Pb}$ & 38.69 & 38.60 \\
\hline$\varepsilon^{205} \mathrm{Tl}$ & -2.0 & 3.9 \\
\hline
\end{tabular}

$1219 \quad$ - concentrations in $\mu \mathrm{g} / \mathrm{g}$

1220 \# - Eastern Aleutian sediment composition from Plank \& Langmuir, 1998 except Nd isotope

1221 composition from Vervoort et al. (2011) and Tl concentrations and isotopes (this study). 


\section{FigureV}

\section{Figure 1}

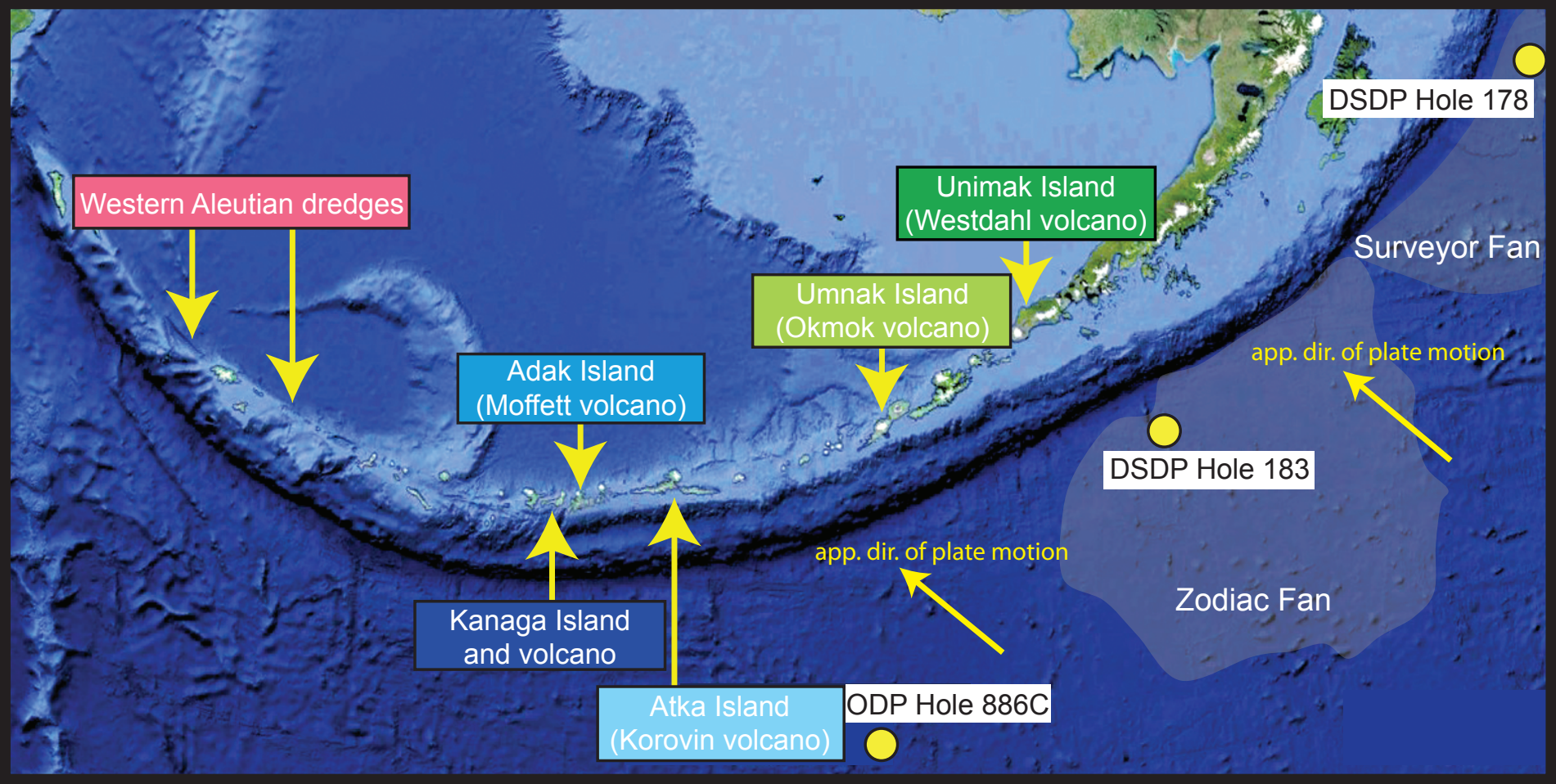


Figure 2

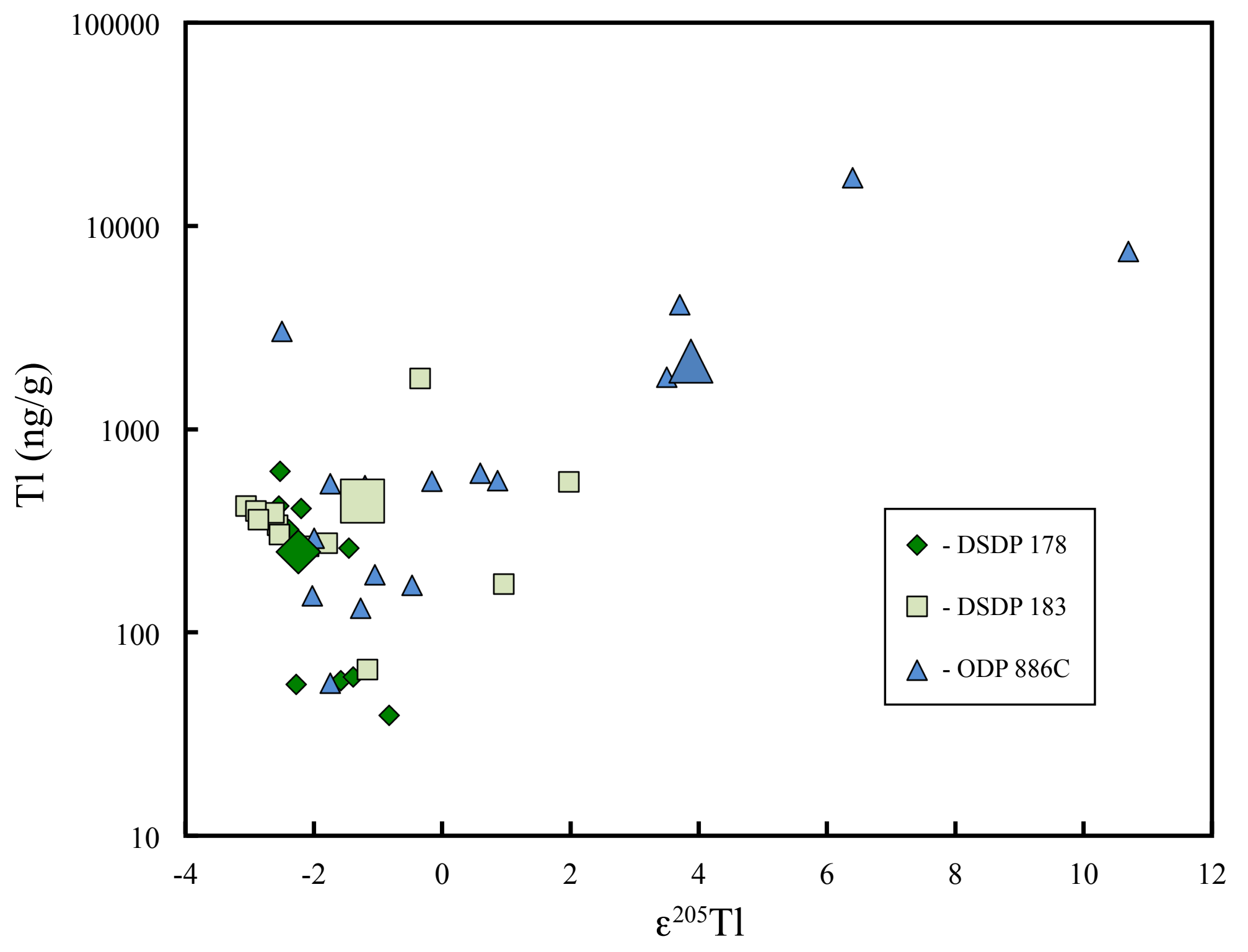


Figure 3

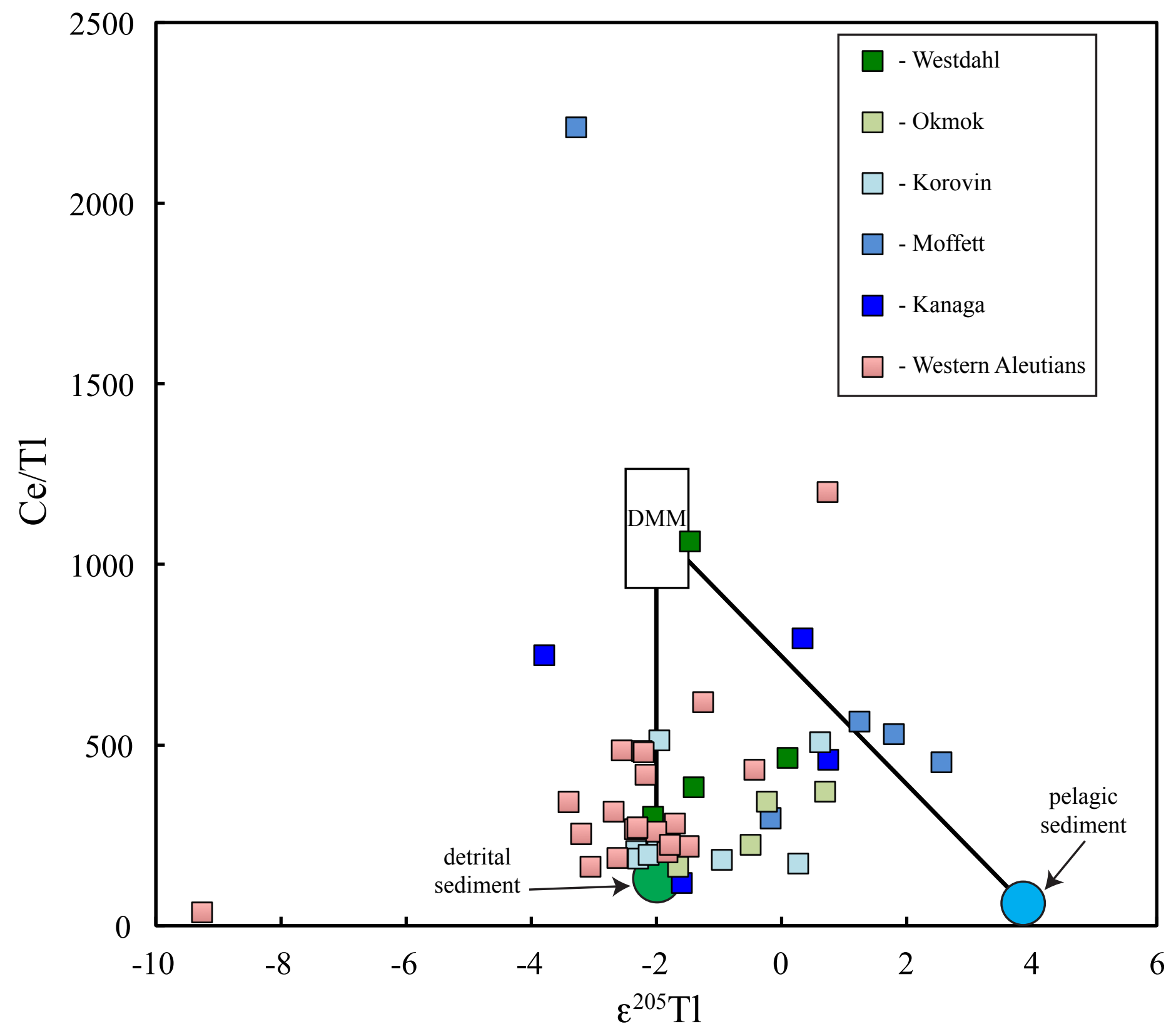


Figure 4

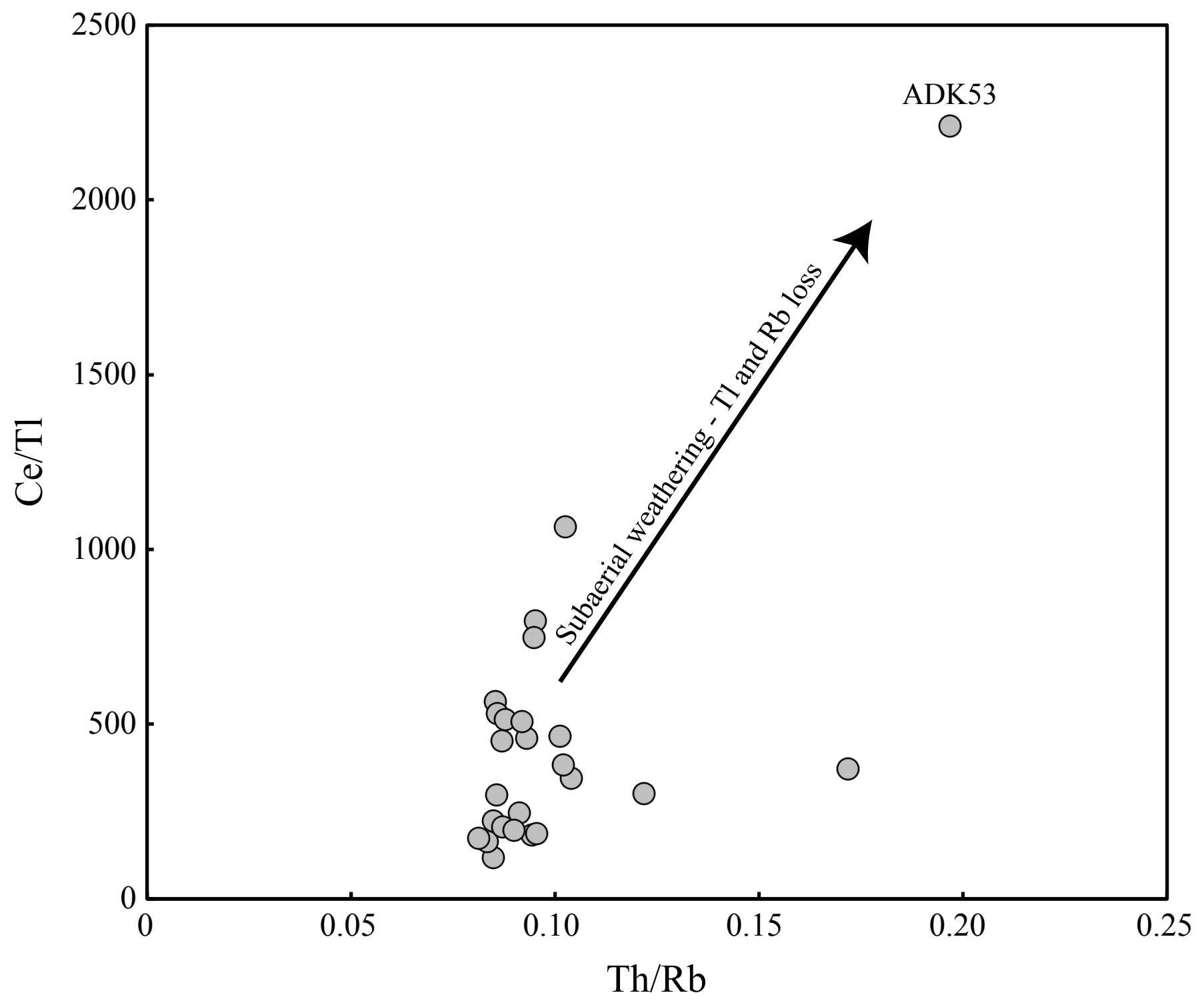


Figure 5

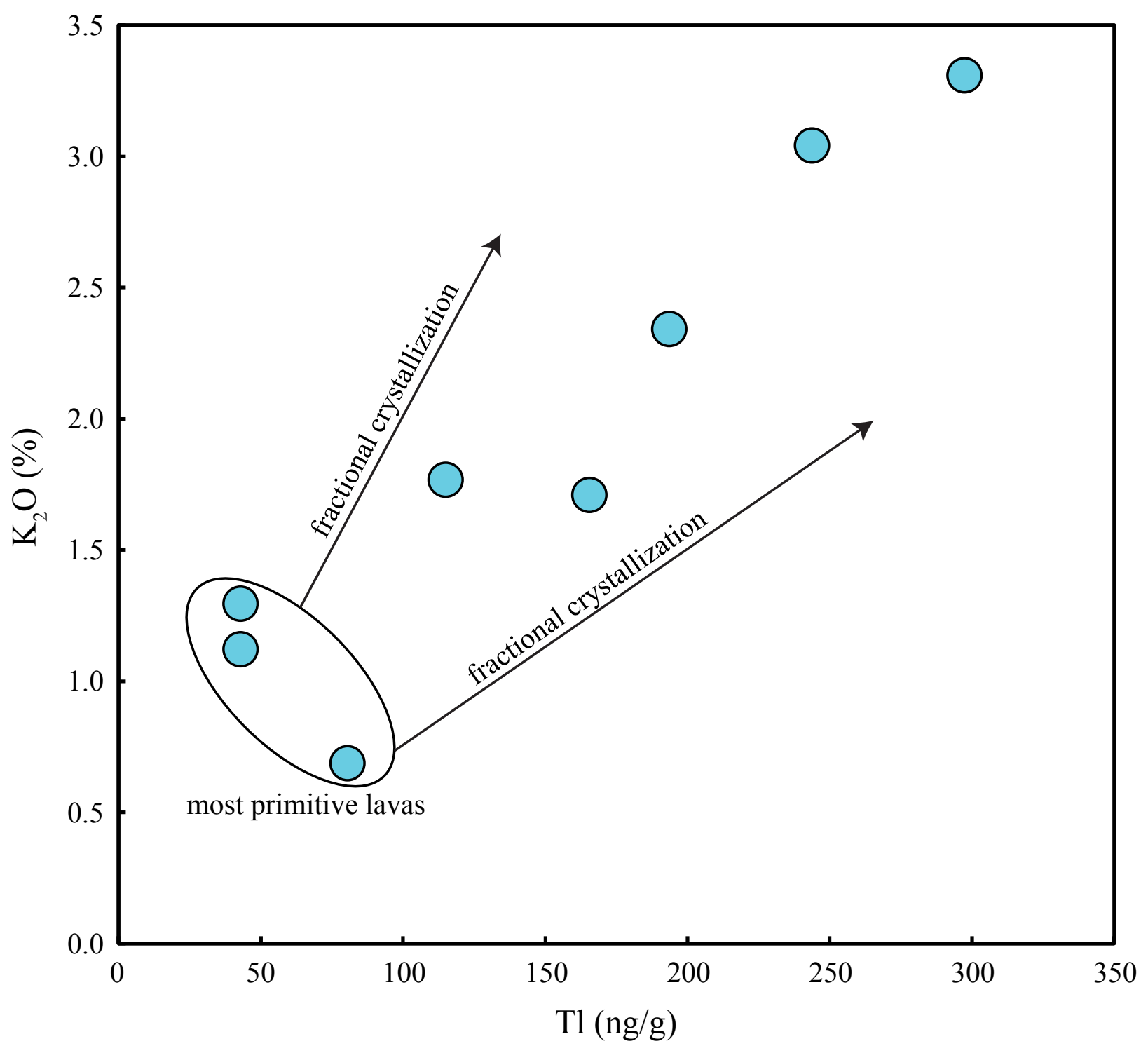


Figure 6

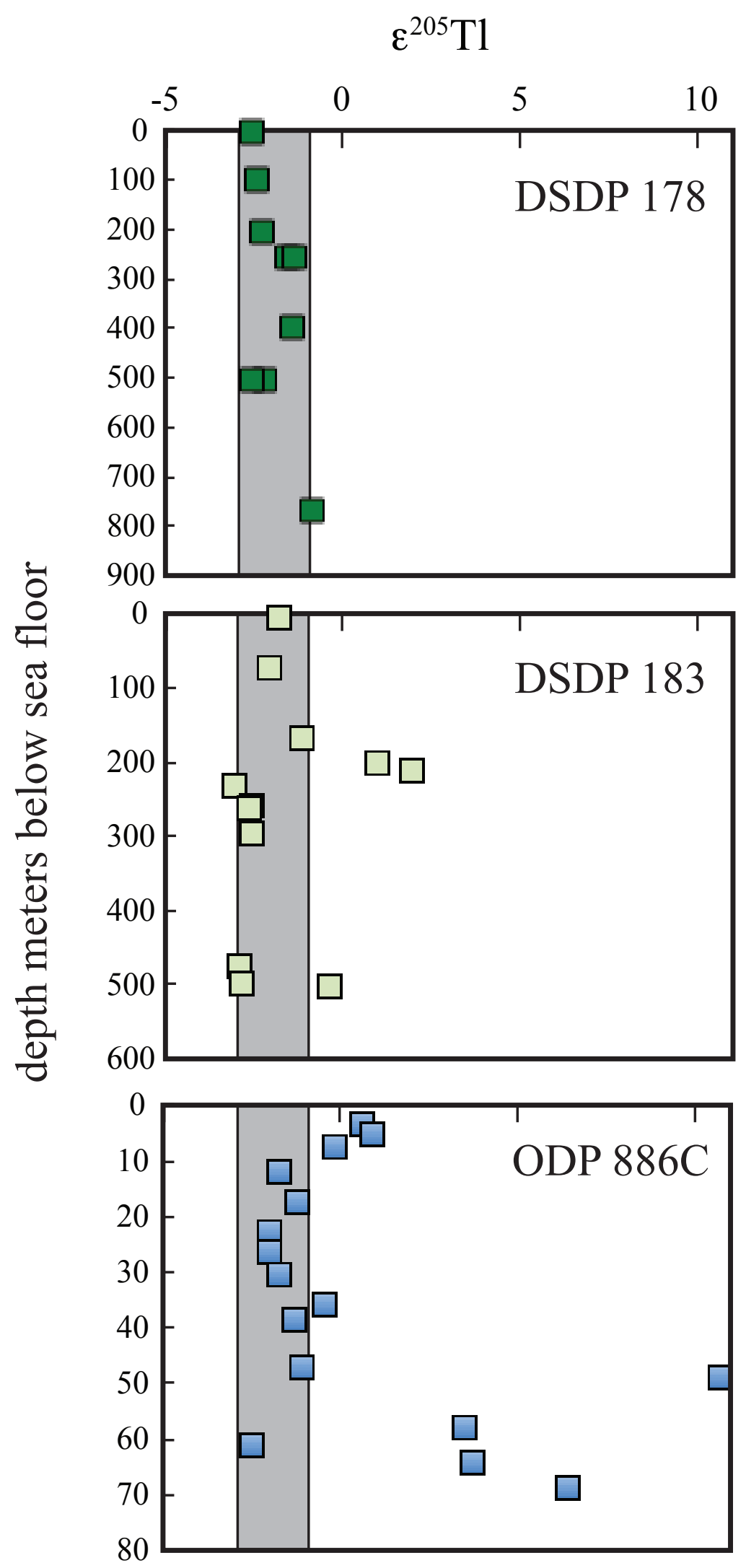


Figure 7
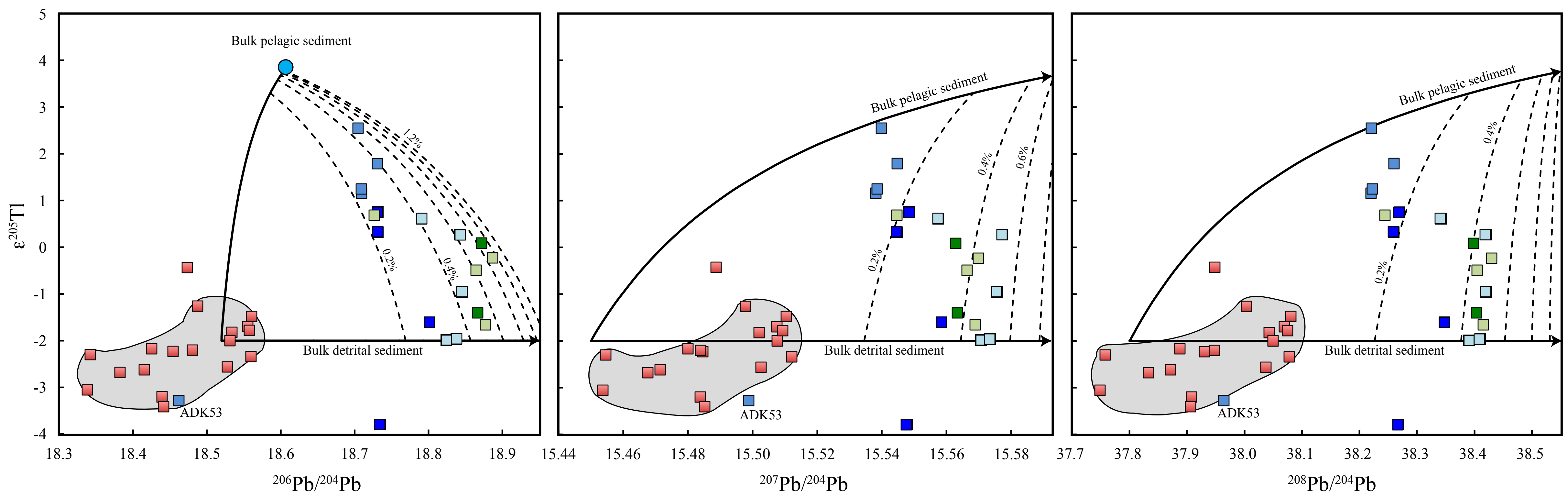


\section{Figure 9}

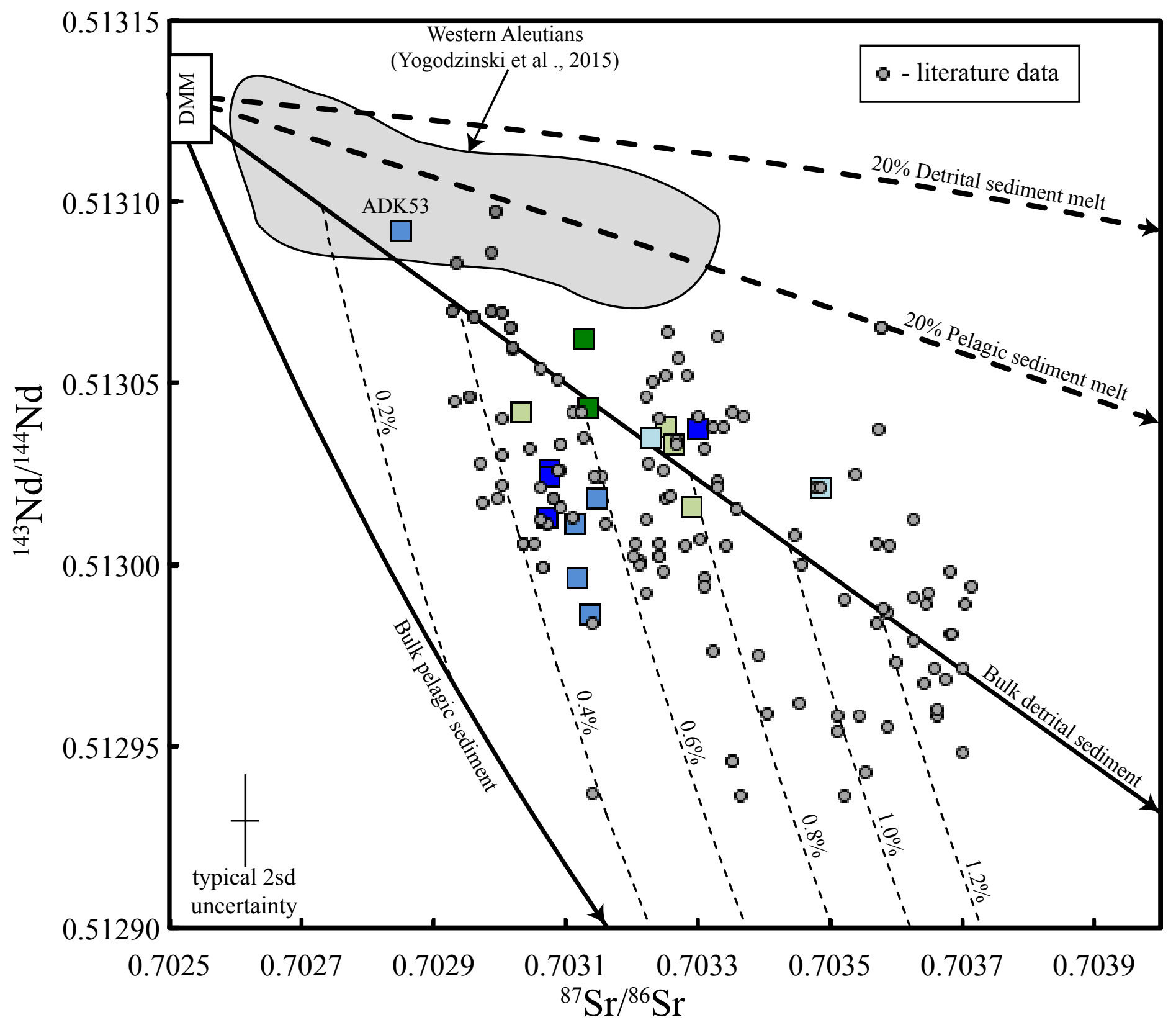


Figure 10

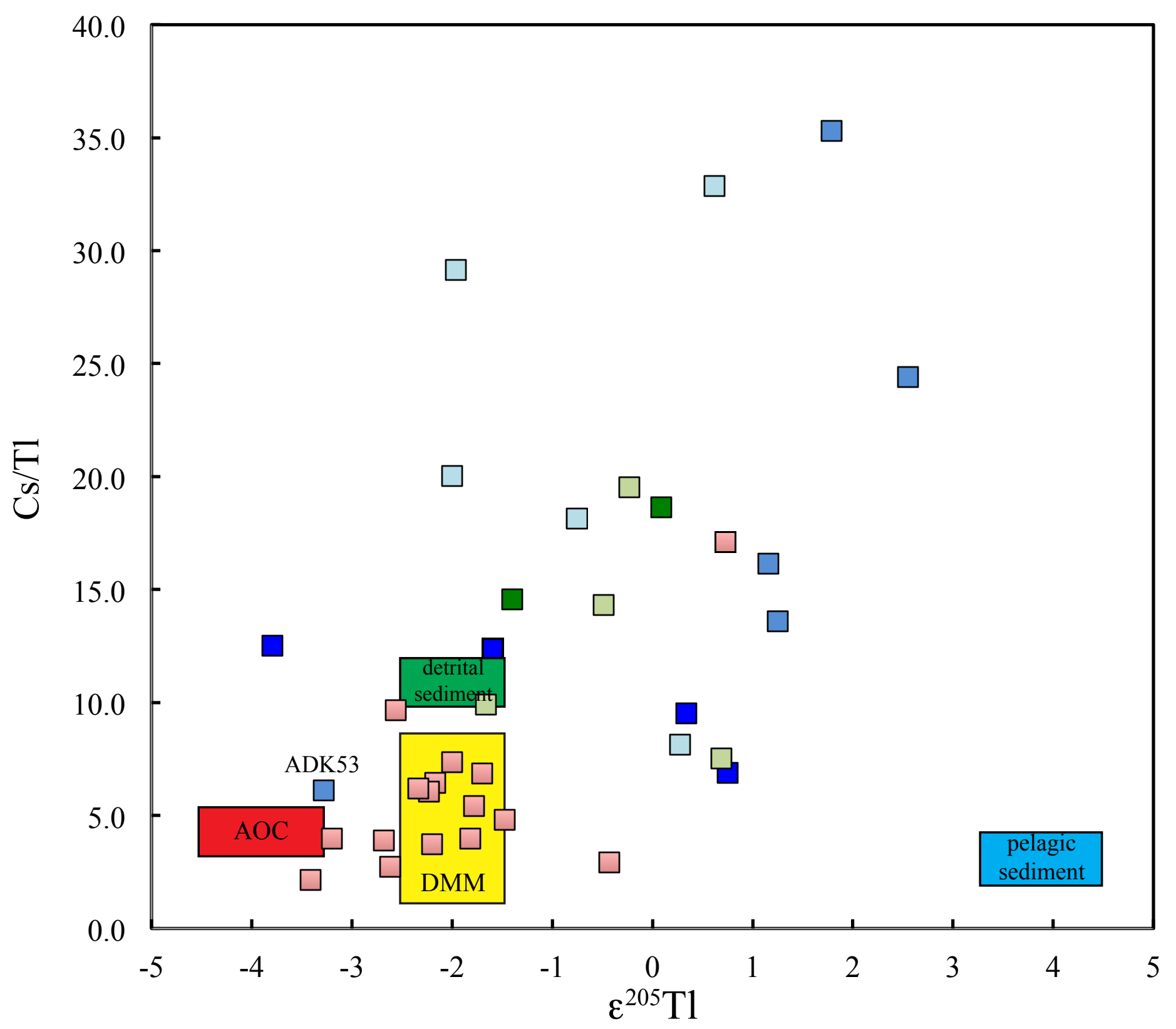

